UC-NRLF

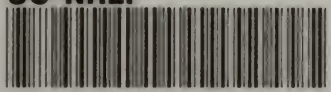
\$B bbl 838 

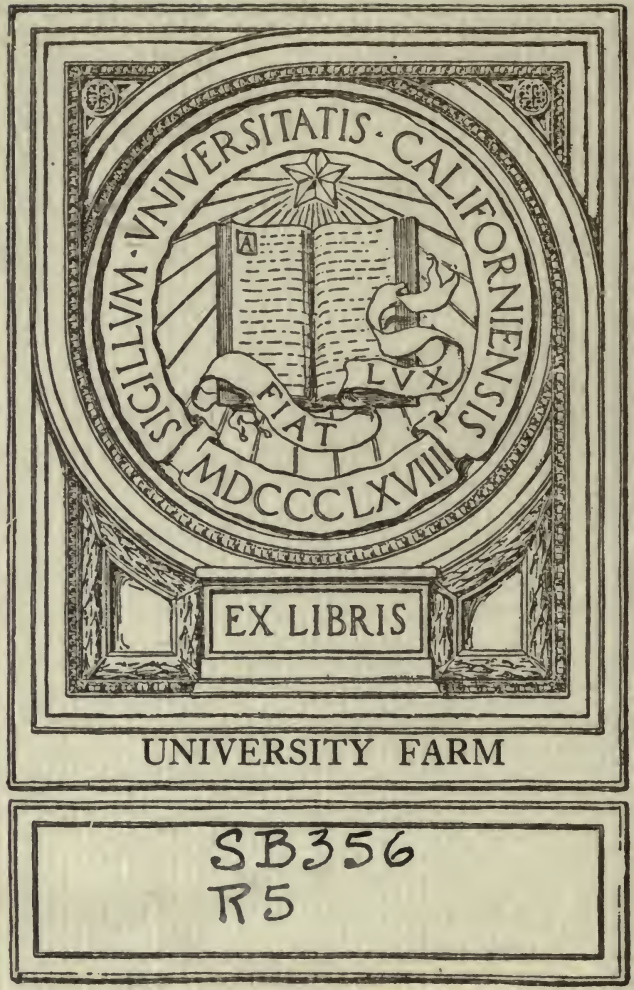

Digitized by the Internet Archive in 2007 with funding from Microsoft Corporation 


\title{
MINIATURE FRUIT GARDEN;
}

\author{
OR, THE CUITIRE OF
}

PYRAMIDAL AND BUSH FRUIT TREES.

"There is no kind of fruit, however delicious, that may not be deteriorated, or however worthless, that niay not be ameliorated, by particular modes of management."-Dr. LINDLEY.

\section{BY THOMAS RIVERS.}

First ANRRIOAN, FRON THE THIRTERNTI ENGLISI EDITION.

\author{
NEW YORK: \\ ORANGE JUDD \& COMPANY, \\ 41 PARK ROW.
}




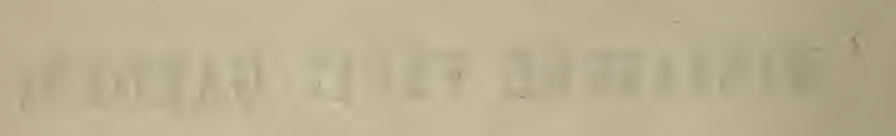




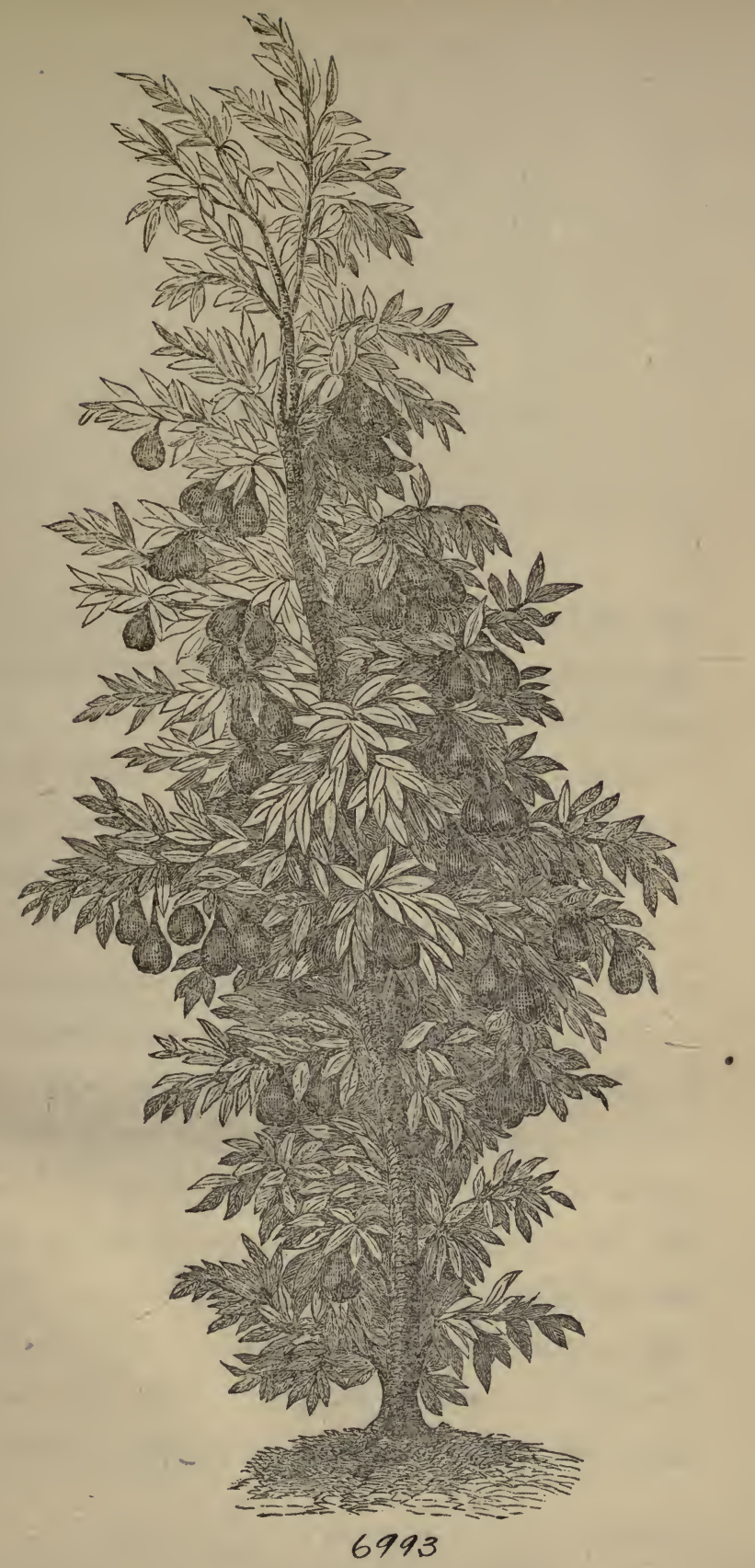





\section{PUBLISHER'S PREFACE.}

A work by the veteran pomologist, Thomas Rrvers, needs no commendation. That it has passed through thirteen editions in England, shows the high estimation in which it is held there. We republish it without any alteration, and without any attempt to Americanize it. No foreign work can be taken by the American gardener as an absolute guide, and there are many things in this which can have little or no application in this country. Yet the work is full of practical suggestions, and no one who has a fruit-garden can fail to find in it many hints of great value. We have no work that treats in such detail of the garden culture of dwarf pear trees. In this country we plant dwarfs, and are dissatisfied at the results they give in ordinary orchard culture. Mr. Rrvers truly says: "It must always be recollected that pears on quince stocks are strictly garden trees, 
and not adapted to orchards." Those who have only a limited space, and wish to grow pears, apples, and other fruits, can, by the system of pinching and rootpruning combined, keep their trees as small as pot specimens. The selection of varieties given here is that suited to Mr. Rivers's climate and locality, and includes some that are not considered valuable with us. The American gardener will, of course, consult home authorities in making out his list of varieties.

NEw YoRK, April, 1866. 


\section{INTRODUCTION.}

Mr attention was drawn to the benefits fruit trees derive from root-pruning and frequent removal about the year 1810 . I was then a youth, with a most active fruit appetite, and, if a tree bearing superior fruit could be discovered in my father's orchard-like nursery, I was very constant in my visits to it.

In those days there was in the old nursery, first cropped with trees by my grandfather, about the middle of the last century, a "quarter,"-i. e., a piece of ground devoted to the reception of refuse trees-of such trees as were too small or weak for customers, so that in taking up trees for orders during the winter they were left, and in spring all taken up and transplanted to the "hospital quarter," as the laborers called it. The trees in this quarter were often removed-they were, in nursery parlance, "driven together" when they stood too thinly in the ground; or, in other words, taken up, often annually, and planted nearer together on the same piece of ground. This old nursery contained about eight acres, the soil a deep reddish loam, inclining to clay, in which fruit trees flourished and grew vigorously. I soon found that it was but of little use to look among the young free-growing trees for fruit, but among the refuse trees, and to the "hospital quarter" I was indebted for many a fruit-feast-such Ribston Pippins! such Golden Pippins! 
When I came to a thinking age, I became anxious to know why those refuse trees never made strong, vigorous shoots like those growing in their immerliate neighborhood, and yet nearly always bore good crops of fruit. Many years elapsed before I saw "the reason why," and long afterwards I was advised by a friend, a F. H. S., to write a crude, short paper on the subject, and send it to be read at a meeting of the Horticultural Society: this paper is published in their "Transactions." I had then practised it several years; so that I may now claim a little more attention, if the old adage that "practice makes perfect" be worthy of notice.

This little work is not designed for the gardens and gardeners of the wealthy and great, but for those who take a personal interest in fruit tree culture, and who look on their gardens as a never-failing source of amusement. In some few favored districts, fruit trees, without any extra care in planting and after-management, will bear good crops, and remain healthy for many years. It is not so in gardens with unfavorable soils ; and they are greatly in the majority. It is to those possessing such, and more particularly to the possessors of sinall gardens, that the directions here given may prove of value. The object constantly had in view is, to make fruit trees healthy and fruitful by keeping their roots near the surface. The root-pruning and biennial removal so earnestly recommended are the proper means to bring about these results, as they place the roots within the influence of the sun and air. The ground over the roots of garden trees, as generally cultivated, is dug once or twice a year, so that every surface-fibre is destroyed and the larger roots driven downwards: they, consequently, imbibe crude watery sap, which leads to much apparent luxuriance in the trees. This in the end is fatal to their well-doing, for the vigorous shoots made annually are seldom or never ripened sufficiently to form blossom-buds. Canker then comes on, and although the trees do not dio they rarely give fruit, and in a 
few years become victims of bad culture, existing in a sort of living death.

There is, perhaps, no fruit tree that claims or deserves our attention equal to a pear. How delicious is a fine melting pear all the winter months! and to what a lengthened period in the spring may they be brought to table! Till lately, Beurré Rance has been our best spring pear; but this is a most uncertain variety, rarely keeping till the end of May, and often ripening in January and February.

The new Belgian pears, raised many years since by the late Major Esperen, and more recently by Monsieur Grégoire, are likely for the present to be the most valuable for prolonging the season of rich melting pears; and of these Joséphine de Malines and Bergamotte d'Esperen are especially deserving of notice; they have the excellent quality of ripening slowly. But improvement will, I have no doubt, yet take place; for pears are so easily raised from seed, and so soun brought into bearing by grafting or budding them on the quince stock, that new and valuable late pears will soon be as plentiful as new roses.

In the following pages it will be seen that I strongly advocate the culture of pyramidal fruit trees. This is no new idea with me. I have paid many visits to the Continental gardens during the greater portion of my active life of business, and have always admired their prramidal trees when well managed, and $I$ have for many years cultivated them for my anusement; but, owing to a seeming prejudice against them among some English gardeners, I was for some time deterred from recorn-

- mending them, for I thought that men older than myself must know better; and when I heard some of our market-gardeners and large fruit-growers in the neighborhood of London scoff at pears grafted on the quince stock, as giving fruit of very inferior flavor, I concluded, like an Englishman, that the 
foreigners were very ignorant, and very far behind us in the culture of fruit trees.

It was only by repeated visits to foreign gardens that this prejudice was dispelled; and when I saw the beautiful pear trees in the Jardin des Plantes at Paris under the management of Monsieur Cappe, alluded to in Gardeners' Chronicle, No. 28, 1847, I felt convinced that our neighbor's excelled us in the management of fruit trees adapted to the open borders of our gardens. I have, therefore, endeavored to make the culture of pyramidal trees easy to the uninitiated; and, having profited largely by experience in attending to it with my own hands, I trust that my readers will benefit by the result.

A humid mild climate seems extremely favorable to the well-doing of the pear on the quince stock. Jersey, with its moist warm climate, as is well known, produces the finest pears in Europe: these are for the most part from trees on quince stocks. The western coast of Scotland, I have reason to know, is favorable for the culture of pear trees on the quince; and within these very few years Ireland has proved remarkably so, more particularly in the south, where some of our finest varieties of pears on quince stocks are cultivated with perfect success. 
THE

\section{MINIATURE FRUIT GARDEN, \\ ETC., ETC.}

PYRAMIDAL PEAR TREES ON THE QUINCE STOCK.

Thene is no description of fruit tree more interesting to cultivate in our gardens than the pyramid-a name adopted from the French, the originators of this species of culture. The word conical would, perhaps, convey a better idea of the shape of such trees, but as pyramidal trees are now becoming familiar things in English gardens, it is scarcely worth while to attempt to give a new name to these very pretty garden trees.

For gardens with a moderately deep and fertile soil, pears budded on the quince stock will be found to make by far the most fruitful and quick-bearing trees; indeed, if prepared by one or two removals, their roots become a perfect mass of fibers, and their stems and branches full of blossom-buds. Trees of this description may be planted in the autumn, with the certainty of having a crop of fruit the first season after planting,-always recollecting that a spring frost may destroy the blossoms unless the trees are protected. It must always be recollected that pears on quince 
stocks are strictly garden trees, and not adapted for orchards.

The most eligible season for planting pyramidal pear trees is during the months of November and December, but they may be planted even until the end of March; in planting so late, no fruit must be expected the first season. Still, I ought to say here that I have frequently removed pear trees on the quince stock in March and April just as the blossom-buds were bursting, and have had fine fruit the same season, particularly if sharp frosts occurred in May. The buds being retarded, the blossoms opened after the usual period, and thus escaped. The experiment is quite worth trying in seasons when the buds swell very early.

If root-pruned pyramidal trees be planted, it will much assist them if about half the blossom-buds are thinned out with a penknife just before they open; otherwise these root-pruned trees on the quince stock are so full of them that the tree receives a check in supporting such an abundance of bloom. About ten or fifteen fruit may be permitted to ripen the first season ; the following season two or three dozen will be as many as the tree ought to be allowed to bring to perfection; increasing the number as the tree increases in vigor, always remembering that a few full-sized and well-ripened pears are to be preferred to a greater number inferior in size and quality.

In the engraving at the commencement of this little volume I have given a faithful portrait of a pyramidal tree of the Beurré de Capiaumont pear, budded on the quince: this was taken in 1846 ; the tree was then 
about ten years old, and had been root-pruned three times. Nothing could be more interesting than this tree, only six feet high, laden with fruit of extraordinary beauty; for in my soil, pears on quince stocks produce fruit of much greater beauty and of finer flavor than those on pear stocks. I have, however, introduced the figure as much to show its imperfection as its beauty: it will be observed that its lower tiers of branches are not sufficiently developed; this was owing to neglect when the tree was young-the upper branches were suffered to grow too luxuriantly. Summer pinching in the youth of the tree is the only remedy for this defect, if it be not well furnished below ; and a severe remedy it is, for all the young shoots on the upper tiers, including the leader, must be pinched closely in May and June, till the lower ones have made young shoots of a sufficient length to give uniformity to the tree. This requires much attention.

The quenouille, or tying-down system, is not practiced in France at the present day; and, in truth, it does look very barbarous and unnatural. The trees trained in this manner in the Potagerie at Versailles are mostly on quince stocks; they are from twenty to forty years old, and are very productive, but very ugly; all the shoots from the horizontal and depressed branches are cropped off apparently in July, as M. Puteau, the director, is, I believe, adverse to the pinching system of M. Cappe. I have not for many years observed a single quenouille in Belgium : all are pyramids, even in the gardens of the cottagers, and in general they are very beautiful and productive trees. In many cases, when on the pear-stock, they are too 
luxuriant, and require root-pruning; but this is not understood by continental fruit-tree cultivators.

Pyramids and bushies are the trees best adapted for small gardens, and not standards such as are planted in orchards. To those conversant with such matters, I need only point to the very numerous instances of rich garden ground entirely ruined by being shaded by large spreading standard, or half-standard unpruned fruit trees. Now, by cultivating pyramidal pears on the quince-apples in the same form on the paradise. stock-the cherry as pyramids and dwarf bushes on the Cerasus Mahaleb-and the plum as a pyramidal tree-scarcely any ground will be shaded, and more abundant crops and finer fruit will be obtained.

THE YOUNG PYRAMID.

If a young gardener 'intends to plant, and wishes to train up his trees so that they will become quite perfect in shape, he should select plants, one year old from the bud or graft, with single upright stems; these will, of course, have good buds down to the junction of the graft with the stock. The first spring, a tree of this description should be headed down, so as to leave the stem about eighteen inches long. If the soil be rich, from five to six and seven shoots will be produced ; one of these must be made the leader, and if not inclined to be quite perpendicular, it must be fastened to a stake. As soon, in summer, as the leading shoot is ten inches long, its end must be pinched off ; and if it pushes forth two or more shoots, pinch off all but one to three leaves, leaving the topmost for a leader. The side shoots will, in most cases 
assume a regular shape; if not, they may be this first season tied to slight stakes to make them grow in the proper direction. This is best done by bringing down and fastening the end of each shoot to a slight stake, so that an open pyramid may be formed-for if it is too close and cypress-like, enough air is not admitted

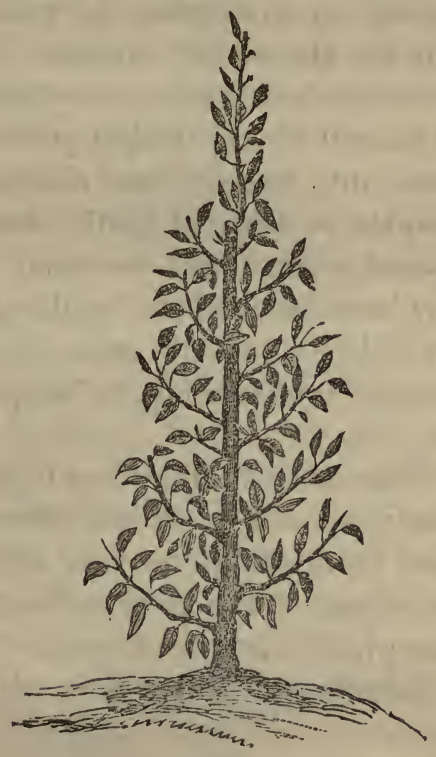

FIG. 1 .

to the fruit. They may remain unpruned till the end of August, when each shoot must be shortened to within eight buds of the stem. This will leave the tree like the preceding figure (Fig. 1), and no pruning in winter will be required.

The second season the tree will make vigorous growth: the side shoots which were topped last 
August will each put forth three, four, or more shoots. In June, as soon as these have made four leaves, they must be pinched off to three leaves, and if these spurs put forth shoots, which they often do, every shoot must be pinched down to one leaf, all but the leading shoot of each side branch; this must be left on to exhaust the tree of its superabundant sap, till the end of August. The perpendicular leader must be topped once or twice; in short, as soon as it has grown ten inches, pinch off its top, and if it break into two or three shoots, pinch them all but the leader, as directed for the first season; in a few years most symmetrical trees may be formed.

When they have attained the height of six or eight feet, and are still in a vigorous state, it will be necessary to commence root-pruning, to bring them into a fruitful state.

If some of the buds in the stem of a young tree prove dormant, so that part of it is bare and without a shoot where there should be one, a notch, half an inch wide, and nearly the same in depth, should be cut in the stem just above the dormant bud. If this be done in February, a young shoot will break out in the summer. ${ }^{1}$

I have thus far given directions for those who are inclined to rear their own pyramids. Time and attention are required, but the interest attached to welltrained pyramids will amply repay the young cultivator.

1 Bare places in the stems of pyramids, and in the branches of espaliers or wall trecs, may be budded toward the end of August with blossom-buds taken from shoots two years old. This is a very interesting mode of furnishing a tree with 1ruit-bearing buds. 


\section{THE MATURE PYRAMID.}

The annexed figure (Fig. 2) is a pyramidal tree in its second and third year, and such as it ought to be in July before its leading side shoots and leading

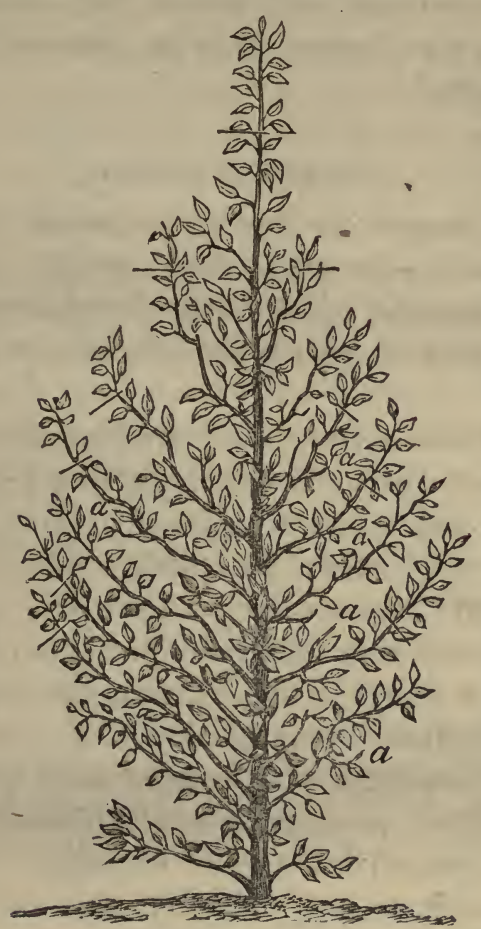

FIG. 2.

upright shoot are shortened. This, as I have said, is best done toward the end of August. The shortening must be made at the marks - ; all the side shoots must be shortened in this manner, and the leading 
shoots; no further pruning will be required till the following summer. The spurs $a, a, a$, are the bases of the shoots that have been pinched in June; these will the following season form fruit-bearing spurs. The best instrument for summer and autumnal pruning is a pair of hooked pruning scissors, called also "rose nippers."

\section{- summer pinching.}

As the summer pinching of pyramidal pears is the most interesting feature in their culture, and perhaps the most agreeable of all horticultural occupations, I must endeavor to give plain instructions to carry it out.

The first season after the planting, about the middle or end of June, the side buds and branches will put forth young shoots; each will give from one to three or four. Select that which is most horizontal in its growth (it should be on the lower part of the branch, as the tree will then be more inclined to spread) for a leader to that branch, and pinch off all the others to three leaves (see Fig. 2, $a, a, a$ ). If these pinched shoots again push, suffer them to make three leaves, and then pinch them to two leaves; but if the horizontal branch has a good leader, it will take off all the superfluous sap, and prevent the pinched spurs from breaking; the buds will only swell, and the following season they will be fruit spurs. The upper shoots of the tree, say to about two feet from its top, should be pinched a week before the lower shoots: this gives strength to those on the lower part of the tree. 
Fig. 3 is a side branch in June, with its shoots not yet pinched; Fig. 4 is a side branch with its shoots $a, a$, pinched in June; $b$ is the leader of the side branch, which should be pinched or cut off at the end of August to $c$.

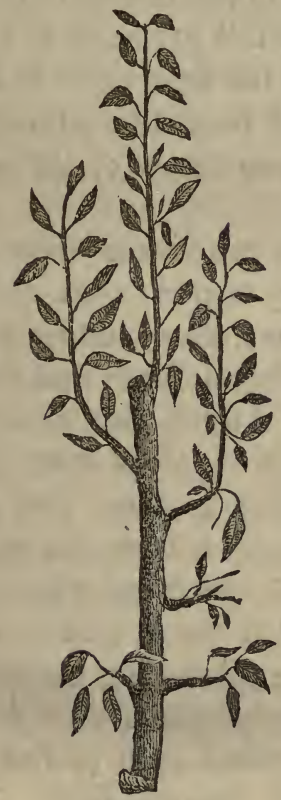

Fig. 8.

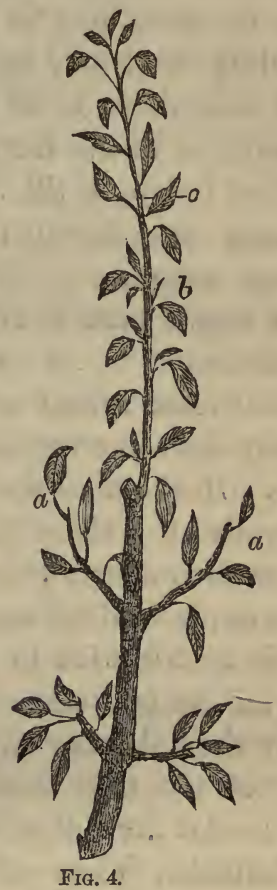

FIG. 4.

In spring the perpendicular leader of the preceding year's growth will put forth numerous shoots, which must be pinched in June in the following manner: those nearest the base, leave six inches in length, gradually decreasing upward, leaving those next the young leading shoot only two inches long. The 
leader of these ready-formed pyramids need not be shortened in summer, as directed for younger trees; it may be suffered to grow till the horizontal leaders are shortened in August, and then left six or eight inches in length; but if the trees are to be kept to six or seven feet in height under root-pruning, this leading shoot may be shortened to two inches, or even cut close down to its base. For tall pyramids of ten, twelve, or fifteen feet, it may be left from eight to ten inches in length till the required height be attained; it may then be cut to within two inches of its base every season.

I ought here to remark that pear trees differ in their habits to an extraordinary degree: some make shoots most robust and vigorous; others, under precisely the same treatment, are very delicate and slender. In the final shortening in August this must be attended to; those that are very vigorous must not have their shoots pruned so closely as those that are less so ; indeed, almost every variety will require some little modification in pruning, of which experience is by far the best teacher. It will, I think, suffice, if I give the following directions for shortening the leaders of the side shoots, and the perpendicular leaders :-All those that are very robust, such as Beurré d'Amanlis, Vicar of Winkfield, Beurré Diel, \&c., shorten to eight or ten inches, according to the vigor of the individual tree; those of medium vigor, such as Louise Bonne of Jersey, Marie Louise, and Beurré d'Aremburg, to six inches; those that are delicate and slender in their growth, like Winter Nelis, to four inches; but I must repeat that regard must be 
had to the vigor of the tree. If the soil be rich, the trees vigorous, and not root-pruned, the shoots may be left the maximum length; if, on the contrary, they be root-pruned, and not inclined to vigorous growth, they must be pruned more closely.

\section{COMPACT PYRAMIDS.}

If pyramidal fruit trees, either of pears, apples, plums, or cherries, are biennially removed, or even thoroughly root-pruned, without actually removing them, summer pinching becomes the most simple of all operations. The cultivator has only to look over his trees twice a week during June, July, and August (penknife in hand), and cut or pinch in every shoot on the lateral or side branches that has made four leaves or more, down to three full-sized leaves. It is just possible that the three buds belonging to these three leaves will put forth three young shoots: as soon as they have made their four or five leaves, they must be shortened to two, and so on with every young shoot made diring the summer, shortening the leading shoot also to three leaves. This method of close pinching represses the vigor of the tree to a great extent, and, in soils that are not very rich, trees under it will not require root-pruning. It is a most agreeable method of treating pyramidal trees, for no straggling shoots are seen, and in small neatly-kept gardens this is a great relief. The pinched shoots in these compact pyramids become too much crowded with blossom-spurs, they should therefore be thinned in winter with a sharp pruning-knife. 
ROOT-PRUNING OF PYRAMIDAL PEAR TREES ON QUINCE STOCKS.

Before entering on the subject of root-pruning of pear trees on quince stocks, I must premise that handsome and fertile pyramids, more particularly of some free-bearing varieties, may be reared without this annual or biennial operation. If the annual shoots of the tree are not more than eight or ten inches long, no root-pruning need be done. I have a large plantation of pear trees on the quince stock, which have been made very handsome and fertile pyramids, yet they have not been root-pruned, neither do I intend to root-prune them. But I wish to impress upon my readers that my principal object is to make trees fit for small gardens, and to instruct those who are not blessed with a large garden, how to keep the trees perfectly under control: and this can best be done by annual, or at least biennial attention to their roots; for if a tree be suffered to grow three or more years, and then be root-pruned, it will receive a check if the spring be dry, and the crop of fruit for one season will be jeopardized. Therefore, those who are disinclined to the annual operation, and yet wish to confine the growth of their trees within limited bounds by root-pruning-say once in two years-should only operate upon half of their trees one season $;^{1}$ they will thus have the remain-

1 In The Junirnal of Horticulture for 1862, page 531, Mr. Lee, of Clevedon, gives an account of his root-pruning practice, which he carries ont extensively on sume hundreds of trees. It appears to be an alternate system of root-pruning, and may be done as follows:-Open a semicirenlar trench on one side of the tree, and frun all the :outs that can be gotat; the following season open a trench of the 
ing half in an unchecked bearing state; and those who have ample room and space may pinch their pyramids in summer, and suffer them to grow to a height of fifteen or twenty feet without pruning their roots. I have seen avenues of such trees in Belgium, really quite imposing. In rich soils, where the trees grow so freely as to make shoots eighteen inches in length in one season, they may be root-pruned annually with great advantage.

The following summary will perhaps convey my ideas respecting the management of pyramids and bushes when cultivated as garden trees. In small gardens with rich soils, either root-prune or remove all the trees annually early in November. In larger gardens perform the same operation biennially at the same season. For very large gardens with a dry, good sub-soil, in which all kinds of fruit trees grow withơut any tendency to canker, and when large trees are desired, neither remove nor root-prune, but pinch the shoots in summer, thin them in winter when they become crowded, and thus make your trees symmetrical and fruitful.

Pyramidal pear trees on the quince stock, where the fruit garden is small, the soil rich, and when the real gardening artist feels pleasure in keeping them in a healthy and fruitful state by perfect control over the roots, should be annually operated upon as follows :-A trench should be dug round the tree, about eighteen inches from its stem, every autumn, just same shape on the opposite sille of the tree (so as to complete the circle), and prine all that can be found there. By this simple method the tree is never checked seriously in its growth, yet enungh to make it form abundance of blossoin-buds. 
after the fruit is gathered, if the soil be sufficiently noist,-if not, it will be better to wait till the usual autumnal rains have fallen; the roots should then be carefully examined, and those inclined to be of perpendicular growth cut with the spade, which must be introduced quite under the tree to meet on all sides, so that no root can possibly escape amputation. All the horizontal roots should be shortened with a knife to within a circle of eighteen inches from the stem, ${ }^{1}$ and all brought as near to the surface as possible, filling in the trench with compost for the roots to rest on. The trench may then be filled with the compost (well-rotted dung and the mould from an old hotbed, equal parts, will answer exceedingly well); the surface should then be covered with some half-rotted dung and the roots left till the following autumn brings its annual care. It may be found that after a few years of root-pruning, the circumferential mass of fibers will have become too much crowded with small roots; in such cases, thin out some of the roots, shortening them at nine inches or one foot from the stem. This will cause them to give out fibers, so thiat the entire circle of three feet or more round the tree will be full of fibrous roots near the surface, waiting with open mouths for the nourishment annually given to them by surface dressings and liquid manure.

Thus far for the gardener who does not mind extra trouble,-who, in short, feels real pleasure in every operation that tends to make his trees perfect in fruitfulness and symmetry. But it is not every amateur

1 If they have not spread to this extent the first season, or even the second, they need not be pruned, but merely brought near to the surface and spread out. 
gardener that can do this, nor is it always required in the south of England, except for small gardens and in rich moist soils, in which pear trees are inclined to grow too vigorously. But with our too often cool moist summers in the northern counties, annual rootpruning is quite necessary to make the trees produce well-ripened wood. In other cases, as I have before observed, shortening the shoots in summer, taking care to produce a handsome pyramidal form, and if they are inclined to grow vigorously, biennial rootpruming will be quite sufficient.

The following will be found a good selection of varieties for pyramidal trees on quince stocks. They may be planted in rows, five to six feet apart, or a square may be allotted to them, giving each plant five or six feet, which will be found amply sufficient for root-pruned trees. Some few esteemed sorts of pears do not grow well on quince stocks, unless "doublegrafted "-i. e., some free-growing sort is budded on the quince, and after having been suffered to grow for one or two seasons, the sort not so free-growing is budded or grafted on it. For ten varieties, placed in the order of their ripening, the undermentioned may with safety be recommended. ${ }^{1}$ (In the following lists, varieties marked thus * may be chosen by those who require only a few trees. $)^{2}$

1. Summer Doyennet*....................... July

2. Beurré Giffard $\ldots \ldots \ldots \ldots \ldots \ldots \ldots \ldots \ldots \ldots \ldots$. August

3. Bon Chrétien (Williams')* .................. September

1 All the varieties recommended for pyramids may also be planted as espaliers to train.to rails in the usual mode.

2 A very good light permanent label for pyramidal and other fruit trees, is a e small piece of zinc, painted with white-lead paint, and written on while moist with a strong black-lead pencll. It should be suspended from a side branch of the tree (not the stem) by a piece of stout copper wire. 
4. Beurré Superfin*

5. Fondante d'Automne

6. Louise Bonne of Jersey*

7. Alexandre Lambré.

8. Benrré d'Aremberg*.

9. Joséphine de Malines*

10. Bergamotte d'Esperen* $\left({ }^{1}\right)$
October

Octoher $m \&$ e. October Nov, and Dec. December March April and May

For twenty add-

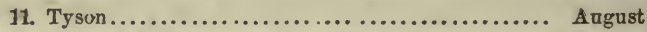

12. Colmar d'Eté............................. September

13. Baron de Mello*........................... October

14. Beurré Hardy* $\ldots \ldots \ldots \ldots \ldots \ldots \ldots \ldots \ldots \ldots \ldots$ October

15. Doyenné Gris.............................. e. October

16. Conseiller de la Cour......................... b. November

17. Winter Nelis*............................ December

18. Beurré d'Anjou............................... \&ecember

19. Beurre̊ Sterckmans........................ January

20. Bezi Mai................................. March to May

The above succeed on the quince, and form excellent pyramids.

ORNAMENTAL PYRAMTDAL PEAR TREES ON QUINCE STOCKS.

There are some few varieties of pears, the trees of which may be made highly ornamental even on a well-dressed lawn, as they grow freely and form naturally beautiful cypress-like trees, at the same time their fruit is of first-rate quality. Such are Summer Beurré d'Aremberg, Baronne de Mello, Duchesse d'Angoulême, Urbaniste, Alexandre Lambré, Beurré Hardy, White Doyenné, Gray Doyenné, Louise Bonne of Jersey, Passe Colmar, Zéphirin Grégoire, Beurré Léon le Clerc, Délices d'Hardenpont, Prince Albert, Délices de Jodoigne, Doyenné de Comice, Bergamotte d'Esperen, and some others.

1 This is a most abundant bearer. A pyramid in the garden of Thomas White, Esq., which was root-pruned in the autumn of 1858 , bore two bushels in 1859 . 
PEAR TREES AS BUSHES ON THE QUINCE STOCK.

It is only very recently that this mode of cultivating pear trees has struck me as being eligible, from having observed the fruit of some of the large heavy varieties, such as Beurré Diel and Beurré d'Amanlis, so liable to be blown off pyramids by even moderate autumnal gales. The trees also of these and several other fine sorts of pears are difficult to train in the

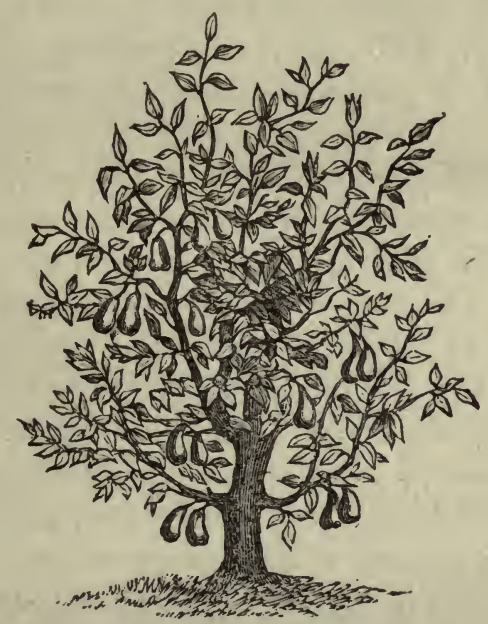

FIG. 5.

pyramidal form; they are diffuse in their growth, and, with summer pinching, soon form nice prolific bushes, of which the preceding figure (Fig. 5), from nature, will give some idea. This summer pinching is quite necessary in bush culture, and is performed by pinching off the end of every shoot as soon as it has made four or five leaves, to three full-sized ones; when the branches become crowded they should be thinned by 
cutting out cleanly with a sharp knife, in winter pruning those that are crowding each other. The biennial removal described below is also necessary, unless in very large gardens where large spreading trees are wished for. Although the taking up and replanting a tree may seem formidable work, it is not so, for the roots, from being frequently removed, become so fibrous near the surface, that an active man can lift and replant one hundred trees in a day. I need scarcely add that if root-pruning, as described in page 14 , be preferred to removal, it may be practiced.

These bushes are admirably adapted for gardens exposed to winds, and if removed biennially they may be grown in the smallest of gardens with great advantage. This biennial removal, or lifting, should be performed as follows:-A trench should be opened round the tree the width of a spare, and from twelve to fifteen inches deep; the tree should then be raised with its ball of earth attached to its root intact. If the soil be light and rich, and the tree inclined to grow vigorously, making annual shoots of more than one foot in length, it may be replanted without any fresh compost; but if, on the contrary, the soil be poor, and the tree stunted in its growth, the following materials may be used:- In low situations near brooks and rivers, a black moor earth is gencrally found: this unprepared is unfit for horticultural purposes, but if dug out and laid in a ridge, and oneeighth part of unslacked lime be spread over it, turıing it immediately and mixing the lime with it, it will become in the course of five or six weeks an excellent 
compost for pear trees. It is good practice to add half a bushel of burnt earth, or the same quantity of sand, to a barrowful of this moor earth. Leaf mold (or rotten manure), loam, and sand, equal parts, form also an excellent compost : in planting, one wheelbarrowful to a tree will be enough. In London suburban gardens, for which these trees are peculiarly adapted, no compost need be given to the trees in replanting, for the soil in them is generally rich. These bush trees offer two very great advantages-they are easily protected from spring frosts when in blossom by covering them with tiffany, and they may be planted from three to five feet apart, so as to be eligible for very small gardens with great facility.

In large gardens in situations exposed to the wind, large bushes may be desirable. In such cases the leading shoots on each branch may be pinched, as recommended for pyramids (page 8); but instead of pinching them to three leaves, they may be suffered to make ten leaves and then be pinched, leaving seven. The trees will, if treated in this manner, soon become large, compact, and fruitful.

The following varieties are well adapted for bush culture, as they are spreading in their growth and difficult to form into compact pyramids, although they may be made into spreading and prolific conical trees. It ought, however, to be mentioned that those sorts, such as Louise Bonne of Jersey, which form handsome pyramids, make very pretty compact bushes by cutting out the central branch to within three feet of the ground; so that pyramids may be easily formed into bushes. I may add that these bush 
pears produce the very finest fruit, from their being so near the heat and moisture-giving surface of the earth.

In situations near the sea-coast, exposed to sea breezes, small fruit-gardens may be formed by inclosing a square piece of ground with a beech hedge or wooden fence, and planting it with bush trees. A piece of ground 500 square feet will be large enough to cultivate 30 trees at 4 feet apart in it, or 25 trees at 5 feet apart. Many a sea-side cottage may thus have its fruit-garden.

\section{LIST OF PEARS ADAPTED FOR BUSH CULTURE.}

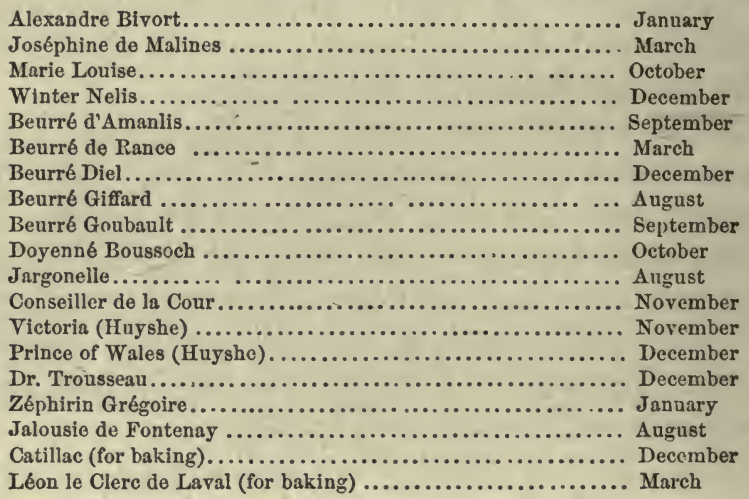

PROTECTORS FOR PYRAMIDAL AND BUSH PEAR TREES.

The weather in spring is often cold and ungenial for the blossoms of pear and other fruit trees; in such seasons pyramids should be protected. This is best done by fixing four stout stakes round a tree; these should be a little taller than the tree, and then be sawn off level. A square piece of calico, or any cheap canvas, should then be nailed on the top of the stakes 
to form the roof, the like material brought round the sides and fastened to the stakes by small nails or tacks, from within eighteen inches of the ground to within eight inches of the top, thus leaving a space between the top and side covering for free ventilation, as the air when heated by the sun will rush out of the aperture at top in a continual stream. These flat-roofed square tents will generally insure a crop of fruit.

Pea-sticks-i.e., stakes with the small brushwood on them-stuck round each tree, and spruce or other fir branches where these can be procured, are also good protectors. For bush trees hay is a capital protector, particularly from those still hoar frosts which are generally so destructive; it should be strewed lightly over them when they are just commencing to blossom. If some brushwood sticks are placed round the bush so as to lean over it, the hay will adhere to the spray,

THE TIFFANY-HOUSE PROTECTOR.

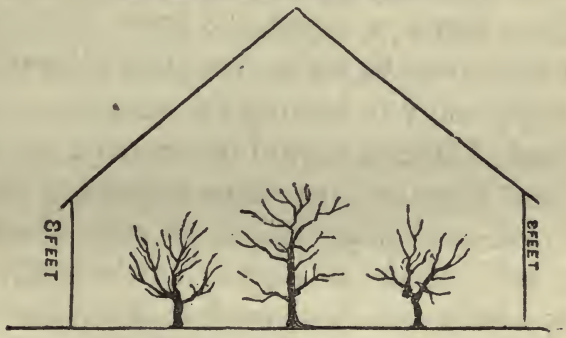

Section of Tiffany-house.

and remain undisturbed by the wind. Tiffany may be used to throw over pear bushes; it is so light that it does no injury to the tender blossoms; it should be taken off on sunny days. There is, perhaps, no better 
protector than old or new netting; if woolen, all the better. This should be thrown over the trees two or three times thick, and suffered to remain on till the fruit is safe from frosts- $i$. e., till the end of May.

Houses built with stakes or slight timber, and the roofs and sides covered with tiffany, have very recently been introduced and found efficient in protecting half-hardy plants from severe frost.

I now propose to erect temporary houses of the same materials to protect dwarf and pyramidal fruit trees while they are in bloom, and I have no doubt but that they will lead to a new era in fruit gardening among amateurs, offering as they do a very cheap method of protection. A border or bed of fruit trees may be eight feet wide and planted with three rows of bush fruit trees as shown in the above section, one row in the centre, and the other rows three feet from it, and the trees three feet apart in the rows, thus occupying six feet of the bed.

A tiffany-house to cover the trees in a bed of the above width may be eight feet wide, three feet high at the sides, and fire high in the centre.

The roof of tiffany should be fastened to the rafters with shreds three or four times double, so as to make a thick pad, and either nailed on with short nails or fastened with screws, so that it may be easily taken to pieces annually the first week in June, for till then we are not safe from spring frosts. The tiffany-house should be placed over the trees the first week in March, unless the season be unusually early, when the middle of February would be better. The sides should be loose, and be turned up night and day in mild 
weather while the trees are in bloom; but in cold, sharp, windy weather in the blossoming season they should be kept down, and fastened to the upright stakes by tying or otherwise.

A tiffany-house twenty-four feet long and eight feet wide will thus shelter twenty-four trees, either bushes or pyramids; if for the latter, the sides of the house should be four feet, and its centre seven to eight feet in height. If it be thought desirable to keep the trees in a comparatively small space, they may be removed biennially in October. If larger trees are desired, the house may be enlarged as the trees grow. A tiffany-house may be from one to 500 feet in length, and twenty in width if desirable, for there are no particular limits to its extent, only the effects of a "March wind" must be thought about when lofty and extensive houses are put up. As measures of economy, the timber and tiffany should be placed in a dry place when removed, and the rafters fastened to the plate and ridge board with screws. A tiffany-house thus treated-"kindly and gently" - will last for several years; and in places where the climate is sufficiently warm to ripen apricots, plums, pears, cherries, and even early peaches, in the open air, they will, I have no doubt, be extensively employed.

PEAR TREES ON THE QUINCE STOCK TRAINED AS UPRIGHT CORDONS.

The French gardeners employ the term cordon for the branch of a fruit tree on which the shoots have been pinched in so as to form a succession of blossombuds. The term, as used by them, is expressive, and 
lately an interesting work has been published by the Rev. T. C. Bréhaut, of Guernsey, on this mode of training, under the title of " Cordon Training of Fruit Trees." It is simply the pinching off the ends of the shoots on a branch, so as to make them form blossombuds, and fruit trees under this mode are planted in an oblique position on walls. With pear trees on the quince stock there is no occasion for this, and the upright or vertical cordon will be found the most convenient mode of training, for which see Fig. 6. To carry out this mode of training, in April, 1849, I planted one of each of some new and esteemed pears on quince stocks against a boarded fence, so that they would quickly come into bearing. The usual method of horizontal training I found would take up too much space, and I could not find room for half the number of trees I wished to plant. In this strait, an old idea came to my assistance-that of cutting pyramidal trees flat, and planting them against walls; and then a modification of the idea came to hand-viz., to plant horizontal espaliers, and to make them perpendicular. In the next page is a figure of one of my vertical cordon pear trees. (Fig. 6.)

The shoots, $a, a$, should be eight inches from the central shoot, and those marked $b, b$, the same distance from those marked $a, a$. This tree with five branches will thus occupy thirty-two inches-say three feet of wall room; a tree with seven branches will require four feet, but as some space ought to be allowed for the spurs on the outside branches, say five feet. If the wall be of a moderate height-eight feet for instance -a tree with seven branches will produce quite 
fruit enough of one sort. This method offers a strong contrast to espaliers on pear stocks, planted in the usual manner, twenty-four feet apart, and trained horizontally; nearly five trees for one will give so many

A VERTICAL CORDON PEAR TREE.

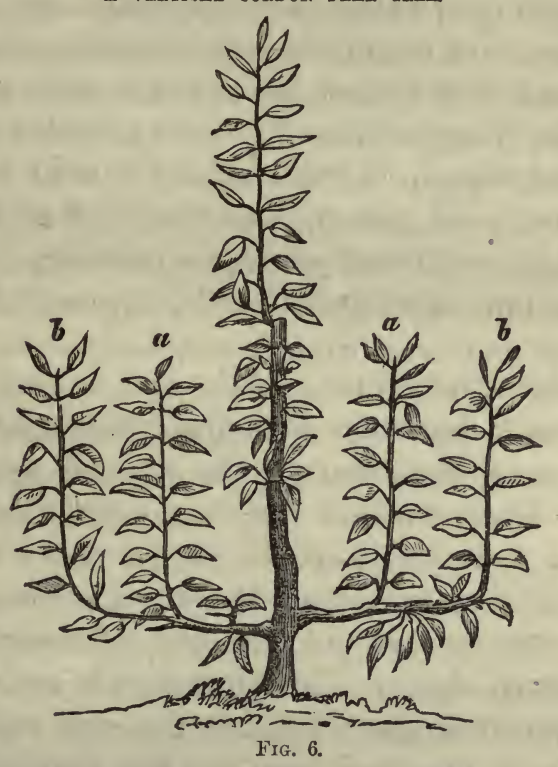

additional chances to the pear cultivator; the single tree may fail, or its fruit may become imperfect, owing to an adverse season; but out of his five trees, he will in every season stand a good chance of having some good pears. A few words will suffice for their management: summer pinching of the shoots to three leaves all through the summer as recommended for pyramids (page 8), and root pruning, or biennial re- 
moval, these operations-like Dr. Sangrado's bleeding and warm water-will do all.

Vertical cordon trees, not only of pears but of cherries on the Mahaleb stock; of plums, and of American apples on the Paradise stock (peach trees are too vigorous in their habit), may be planted against walls in gardens, if of a moderate size, to great advantage. As so much variety may be had in a small space, let the reader imagine himself to have a brick wall with a southern aspect, 20 feet long and 8 or 10 feet high. According to old notions, this would afford space for one tree, but with vertical cordon training, I repeat, five trees may be cultivated, and thus give five chances to one.

If upright trained trees on the quince stock can not be procured, those that are trained horizontally, with five or seven branches, may be planted against the wall or fence destined for them; and their young shoots, $a, a$, and $b$, $b$, in Fig. 6 , be made to curve gently till they are perpendicular-the young shoots of pear trees are very pliable, and will easily bend to the required shape. The lower part of each shoot in such cases must be fastened to the wall with shreds and nails, in the usual way, and the remaining part brought round to an upright position. If they are more than two feet in length, each of these shoots must then be shortened to it. These shortened branches will, in May, each put forth two or three shoots. As soon as they have made four leaves, pinch all but one on each branch to three leaves, leaving the topmost one to each shoot, $a, a$, and $b, b$, as above, also to the leader. You will thus, if your tree be five branched, 
have five young leading shoots. As soon in June as they have attained to eight inches in length, pinch off the end of each; and when they break into two or three shoots as before, pinch so as to leave the spurs with three leaves, and the leading shoot unpinched to each branch. This may be repeated, if the soil be rich, two, three, or four times in the summer. Your tree will soon reach the top of the wall, and every bud in the five branches will be perfect-either a blossombud, or one in embryo. When every branch has reached the top of the wall, commence root-pruning (or biennially lifting them) in autumn, the directions for which are-given in treating of pyramidal trees. These may be followed exactly; and if so, the trees will be kept in a stationary bearing state. It must be recollected that the spurs on the branches will often put forth shoots even while bearing fruit; these must be pinched in to three leaves.

I may as well hint to the reader that, if larger trees are wished for, so as to give more fruit of each sort, trees with nine upright branches may be planted seven feet apart, or trees with eleven upright branches, nine feet apart. Trees, however, can seldom be purchased with shoots so numerous; young trees must, therefore be planted, and cut back annually for two or three years, till the proper number of perpendicular shoots are supplied. It may happen that trained trees with five or seven branches can not be procured, perhaps trees with only three shoots, two horizontal and one leading shoot; in such cases they must be cut back, leaving five buds to each shoot, and the young shoots in June trained as required. 
Pyramidal trees cut flat on the side to be placed next the wall, and planted against walls or fences, will give almost a certain crop. Their shoots must be pinched, and trained so as to form a handsome semi-pyramidal tree, which, when it has reached the top

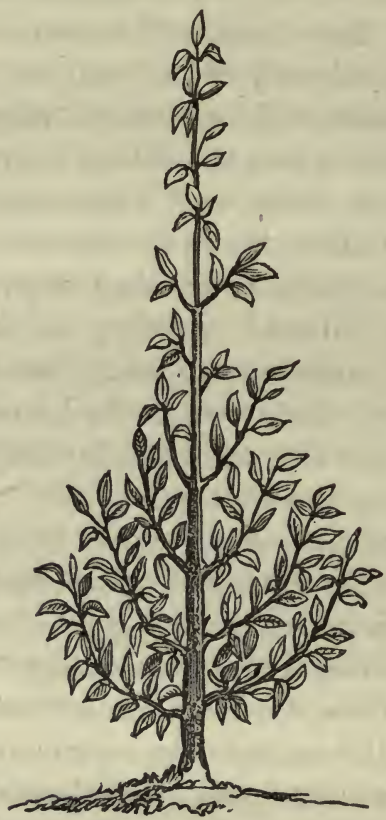

FrG. 7.

of the wall, must be subjected to biennial removal, so as to keep it in a stationary fruitful state. Annexed I give a figure (Fig. 7) of a young pyramid planted against a south-east fence.

It will, I trust, be seen how economical of space are 
these methods of training pears to walls; and I know of nothing in fruit culture more interesting than a wall of upright espaliers, or of pyramids full of fruit. Let us only consider that a wall 100 feet long will accommodate four trees on the pear stock, trained in the usual horizontal mode; the same wall will give " ample room and verge enough" to twenty trees on the quince stock, trained perpendicularly ; if their young shoots (all but the leaders) are pinched in to three leaves all the summer, no root-pruning will be needed. They are also invaluable for planting against walls between old trees where there are bare spaces, as is so often the case; for they soon fill up such vacancies, and bear abundance of fine fruit. A selection of varieties for wall trees will not here be out of place.

\section{UPRIGHT TRAINED TREES ON QUINCE STOCKS. \\ FOR SOUTH OR SOUTH-WEST WALLS. \\ Crassane* \\ Summer Doyennés \\ Chaumontel \\ Passe Colmar \\ Glon Morcean* \\ Beurré Hardy \\ Van Mons (Léon le Clerc) \\ Gansel's Bergamot'2}

WOR WIST OR NOETH-WEST WALLS.

Beurré Diel*

Beurré d'A manlis

Beurré de Rance

Beurré Sterckmans*
Beurré Superfin*

Marie Lonise*

Lo uise Bonne of Jersey

Joséphino de Malines*

FOR EAST OR BOUTII-EAST WALLS.

Beurré Easter*

Beurré d'Aremberg*

Bergamotte d'Esperen

Winter Nelis*
Doyenné d'Alençon

Beurré de Caen

Consellier de la Cour

Beurré d'Anjou*

The above varieties grafted on pear stocks are

1 This will ripen on walls toward the end of June, quickly followed by Citron des Carmes.

2 It is not generally known that this fine rariety, proverbially a shy bearer, becomes, when double grafted on the quince stock, one of the most abundant bearers. 
equally adapted for their several aspects. In shallow, gravelly, or chalky soils, pear's on pear stocks are to be preferred for walls.

It is almost useless to plant dessert pears against north or north-east walls, as the fruit, unless in very warm seasons, is generally deficient in flavor. The only varieties that offer the least chance of success, and that only in a warm climate with a dry soil, are Marie Louise, Louise Bonne of Jersey, and Beurré Superfin. It is far better to plant against such aspects baking or stewing pears, such as Catillac, Bellissime d'Hiver, and Léon le Clerc de Laval; the Vicar of Winkfield is also a good north wall pear-it bears well and stews well. In the north the finer sorts of pears must be cultivated on south walls.

In recommending pears on quince stocks as pyramidal trees for cold soils and situations, even in the far north, I may appear theoretical; but from my own experience, in some very cold and clayey soils in this neighborhood, I feel sanguine as to the result, for I have observed in my frequent visits to the pear gardens of France that many sorts are often too ripe. Now, this is just the tendency we require. In our cold and moist climate, most certainly, pears will not get too ripe, more especially in the north of England and Scotland. Some years since I received a letter from a correspondent living in a hilly part of Derbyshire, from which I give an extract:- "I have tried Beurré Diel, Beurré de Capiaumont, Marie Louise, and Williams's Bon Chrétien, on pear stocks, all of which bear well as standards, but their fruit does not come to perfection-always remaining quite 
hard till they decay at the core. I have placed the fruit in a hot-house, but have never succeeded in ripening them. Williams's Bon Chrétien we can only use for stewing." This seems to show that cold hilly situations are not favorable to the cultivation of pears as standards. I have recommended some pears on quince stocks, and have heard of a favorable result.

CORDON PEARS ON TRELLISES UNDER GLASS.

Some few years since a very ingenious method of growing peaches and nectarines on trellises, over which were placed movable glass lights, was invented by Mr. Bellenden Ker. In warm 'and sheltered gardens this mode of culture answers very well for peaches, but in cool climates there is not day-heat enough stored up, as in houses, to act upon the fruit. Cheap orchard-houses are, therefore, to be preferred to these cheap trellises for the above kinds of fruits, unless the garden be small and much sheltered.

Soon after I had built my trellis for peaches, it occurred to me that the system applied to pear culture would do well, and so I built a trellis 60 feet long and 7 feet wide; on this I planted upright espalier pears on quince stocks. Fig. 8 is a section of this trellis,

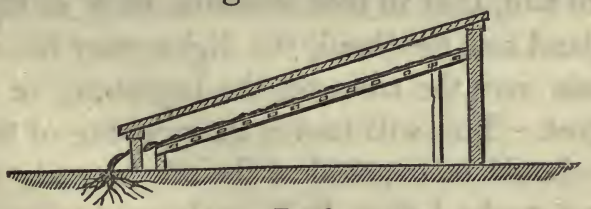

FiG. 8.

and Fig. 9 is a front view of a pear tree trained to it 
in the upright method. My trellis was planted eight years ago, and has now on it twenty fine trees, about ten years old, and in full bearing. They were planted three feet apart, as it was my first experiment, and

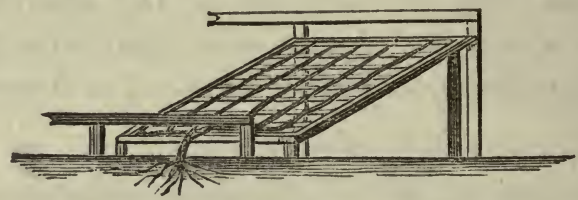

Fig. 9.

are now a little crowded; four feet apart will be found the proper distance. I have never seen any thing more interesting in fruit culture than this trellis covered with pears, for, owing to its being near the ground, the radiation of heat and moisture gives the fruit a size and beauty rarely seen even on walls.

The lights should remain over the trees till the beginning of July, and then be removed, suffering the fruit to ripen fully exposed to the sun and air. It seems that the glass over the fruit in its young state serves to develop its growth in a remarkable manner, for rarely is a spot seen on pears grown on these trellises; they have a clear, beautiful appearance, much like those grown in the warmer parts of France. I ought to add, that in cool climates, such as the north of England and Scotland, the lights may be suffered to remain over the trees till the beginning or middle of August. This will hasten the ripening of the fruit, but it should be exposed to the air in early autumn for some weeks before it is gathered (unless the climate be particularly cold and stormy), or it may suffer in flavor. Pears ripened under glass are apt to suffer 
in this respect. I have, however, very recently received the following communication from a very clever fruit-cultivator living in Ireland :-

"Let no one persuade you that pears grown in a well-ventilated orchard-house are not equal to those outside; I can give strong evidence to the contrary. In my house there was a small Louise Bonne on the quince stock, in an 11-inch pot; it bore 23 splendid pears, as far superior to the same fruit grown in the open air, as it was possible to be. They were not, I admit, high-colored, but they attained a richness and flavor that I thought Louise Bonne did not possess."

The pear trellis, of which the section and front view (Figs. 8 and 9) will give a correct idea, is of the most simple description. A row of larch or oak posts must be driven into the ground 6 feet apart, and another row in front; on these should be nailed plates, 3 inches by 2 , and then bars, 3 inches by 1 , placed flatwise, from front plates to back, 3 feet apart; across these, common tiling laths should be nailed, six inches asunder. This will form the trellis, as seen in Fig. 9. The supports for the lights are formed in the same manner, by a row of posts at the back, and the same for the front, on which are nailed plates of the same dimensions as those for the trellis; a cross-piece should be nailed to front and back plate at each end, to keep the supports for the lights from giving way. The structure with the lights, when resting on the back and front plates, has exactly the appearance of a large garden frame without back, front, or ends. Under the lights the trellis is formed with a sharp slope upward to the back; for unless the front of the trellis 
is within six inches of the ground, it will be difficult to bend the trees to the required position. By this simple contrivance, pears (and eren peaches and nectarines, in warm gardens) may be grown in any corner of the garden, with a south or southwestern exposure-for it is scarcely necessary to add that the lights should slope to the south or south-west, so as to have all the sun-heat possible.

The most eligible dimensions for a trellis, I find from experience to be as follows:-

\section{Glass Lights.}

Eight feet long, three feet wide.

Height from ground at back, three feet six inches.

Height from ground at front, one foot six inches.

\section{Trellis.}

Height from ground at back, two feet six inches.

Height from ground at front, six inches.

Distance from glass lights, one foot.

The front border should be raised to a level with the front of trellis ; this will leave twelve inches between the front ends of the lights and the surface of the front border, which will be quite enough for ventilation ; indeed, the draught in windy weather is inclined to be too sharp. I find, therefore, furze, or other evergreen branches, placed along the front, between the glass and the border, and a mat nailed at the back, excellent checks to excessive ventilation in cold frosty weather. They may remain there till the beginning or end of June; the latter, if the weather be cold and stormy. The lights are fastened to the plate, back and front, by a hook-and-eye; they are thus easily removed to prune the trees and gather the fruit.

I was induced, as I thought, to improve upon Mr. 
Ker's plan, by having my first trellis within eight inches of the glass - for I calculated, the nearer the glass the better the chance of success in early ripening; but I suffered for my innovation. My peach trees were planted in March, 1848; they made during the summer, with the lights constantly on, beautifully matured shoots, and in March and April, 1850, were gay with blossom. The winds were cold, the nights frosty; but, owing to the extreme ventilation, which kept every bud and shoot dry under the glass, not a blossom was injured by the sharp winds, and the trees were covered with fruit. On the fatal $3 d$ of May, however, in 1850, a still hoar frost-the thermometer down to $23^{\circ}$-destroyed all my hopes, for, owing to the trees being too near the glass, every fruit was blackened and destroyed: a single mat would have saved them; but I was not at home, and my pet trees were forgotten. Do not, therefore, have the trellis nearer the glass than twelve inches.

It will be seen that I employ smaller lights, which are easily removable for purposes of culture, and a smaller trellis than that described by Mr. Ker in the seventh edition of this work. I find from experience this smaller edition of the Kerian trellis much to be recommended for small gardens.

HORIZONTAL CORDON PEAR TREES ON DWARF WALLS.

Having had occasion within these two years to erect a large number of four-inch brick walls on which to train young peach trees, I have been much struck with their eligibility for pear trees on quince stocks. A very large number of trees may be cultivated in this manner on a small piece of ground. 
My walls have a nine-inch foundation of three courses of brickwork in the ground, and they are carried up to four feet above the surface (it is scarcely safe to build them of a greater height), with nine-inch piers fifteen feet apart. The coping for them is made of boiling coal-tar mixed with lime and sand to the consistence of mortar, which is placed on the top of the walls thus $\sim$ so as to carry off the water. This is a most cheap and efficacious covering-it can scarcely be called a coping, as it does not project over the edge of the wall. A coping of Portland cement is even better, as it holds the wall together.

The best description of bricks for these light walls are the patent perforated bricks, but common stock bricks will do. The very best lime should be used (I have found the gray Dorking lime excellent), but any kind of lime made from limestone will answer well; that made from chalk in this county is not strong enough. Their cost, as I learn from my bricklayer, is about six shillings the yard in length; thus a wall of the above height, twenty yards long, should cost six pounds. In places where bricks are cheap, they may be built for less; if they are dear and at a distance, their carriage will add to the expense. My walls are six feet apart, and stand endwise, N. E. and S. W.; so that one side of each wall has a S. E. aspect, the other a N. W.; on the former may be grown the late-keeping pears, on the latter the earlier sorts, that ripen from October till the end of November. We thus have one excellent aspect-the S. E. ; and one tolerably good-the N. W.: so that no wall space is lost. 
The pear trees for these dwarf walls should be grafted on quince stocks, and trained horizontally. They may be planted five feet apart at first, and when their branches meet they should be interlaced, as in Fig. 10, and if necessary-i.e., if the shoots be long enough-they may be trained over the stems, so that the wall is completely furnished with bearing branches. At the end of five or six years every alternate tree may be removed, leaving the permanent trees ten feet apart. I advise planting thus thickly, because I

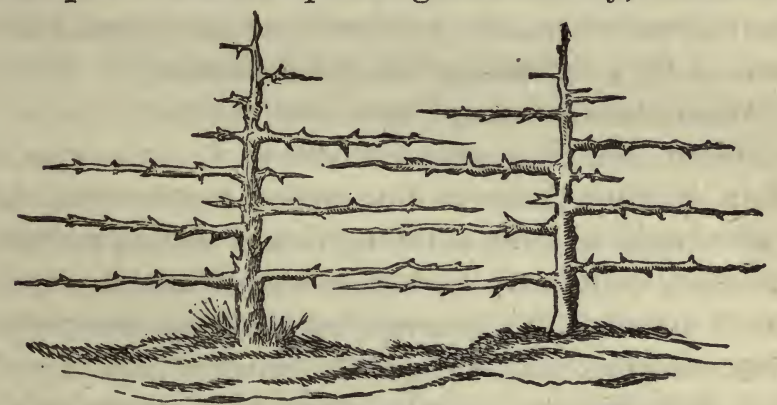

FIG. 10.

know from experience, that the temporary trees will fill the walls, will bear a good quantity of fruit, and look more satisfactory than if they are planted thinly. When removed they may be planted out for espaliers, or fresh walls built for them. I have some trees that have been planted six years; but I find that, owing to the soil not being rich, they have not grown rapidly, and need not yet be removed, as their branches only just cover all the fence to which they are trained.

If, owing to the soil being rich, the trees are inclined to grow vigorously and not bear, they should 
be lifted biennially; but pears on quince stocks will be sure to bear abundantly.

These dwarf walls, when covered with well-trained trees, have a neat and charming effect; and the trees may be so easily protected by sticking branches of evergreens in the ground and letting them rest against the wall, or by wooden shutters, placed on the ground at an angle so as to rest against the wall; but I intend to be more luxurious, and to have cheap glass lights, in lieu of shutters, placed against the walls, and suffered to remain, so as to cover the trees till the fruit is fully formed, or till the first week in June, when all fear of damage from frost is over.

Where two or more walls are built, or a square piece of ground deroted to them, a cross wall or walls should be built at the north-east end, to prevent the sharp current of wind from the north-east, which would blow up the intervals between the walls with great violence. It is surprising what a quantity of fruit may be grown on a small space of ground with the aid of these walls! Peaches, nectarines, and apricots may be grown on the S. E. aspect, but the trees must be kept in check by biennial removal. I have at this moment more than two thousand yards in length of them, and I intend to add to them annually, so convinced am I of their economy and utility. They seem to me most particularly suited to suburban, or what are commonly called cockney gardens. How pleasant to be able to have a brick wall twenty yards long for six pounds, or ten yards long for three pounds! and how delightful to be able to grow one's own "wall fruit!" On a wall ten yards long, five 
peach and nectarine trees may be trained, and many dozens of fruit produced annually. These dwarf walls for the cultivation of peaches, nectarines, and apricots must, however, differ from those for pear trees, and be built so as to give a south or south-west aspect for the front, a north or north-east for the back. The latter may be planted with Morello cherries. To carry out the cultivation of the above-mentioned trees on dwarf 'walls, it is absolutely necessary to take them up biennially in November, and replant them in the same place. ${ }^{1} \quad$ They will not require any compost to their roots, for peach, nectarine, and apricot trees are generally by far too vigorous in their growth. In some of the London suburban gardens the soil is so rich, that annual removal, particularly with apricots, may be found to be quite necessary. In country grardens where the soil is poor, a dressing of manure on the surface over the roots two inches deep will be of service. The peach trees on my experimental wall are removed biennially. The soil is not rich, yet they are almost too vigorous; they bear fine fruit and give good crops.

A matter of great consequence in peach tree culture on walls is to keep the surface of the soil solid; if, therefore, the trees grow too vigorously, so as to require removal, say in October, the soil, after the tree is planted, should, after becoming dry, be rammed with a wooden rammer, so as to be as solid as a common garden path. In spring this hard surface should be covered with a slight deposit of thoroughly

1 It is a prudent practice in all cases of biennial removal to remove half the number of trees in alternate years, for in dry seasons those recently removed may be too much checked in their growth. 
decayed manure, which will be all the culture required.

\section{ESPALIER PEARS ON QUINCE STOCKS.}

Pears on the quince may be cultivated as horizontal espaliers or cordons by the sides of walks, or trained to lofty walls with much advantage, as less space is required. Horizontal espaliers, or wall trees, on the pear stock, trained to walls of the usual heighti.e., from ten to twelve feet-require to be planted twenty feet apart, while those on the quince may be planted only ten feet apart; this in a small garden will allow of much greater variety of sorts to supply the table at different seasons. With these the same high culture, if perfection be wished for, must be followed; the trees carefully planted, so that the junction of the graft with the stock is even with the surface of the mound formed as directed for pyramids. The pruning of wall pear trees has always been a subject of controversy with gardeners, as they are inclined to grow too vigorously. If it be thought desirable to have trees of large growth, so as to cover a high wall, and yet be highly fertile, it is much better to root-prune than to prune the branches. With such trees it need not be done so severely: biennial root-pruning will be quite sufficient, commencing at eighteen inches from the wall, after the tree has had two seasons' growth, cutting off the ends of all the roots at that distance from the wall, and increasing it by six inches at every biennial pruning, till a distance of six feet from the wall is reached. When this is the case, the roots must be confined 
to the border of that width by digging a trench biennially, and cutting off all the ends of the roots at that distance from the wall.

I may, perhaps, make this more plain by saying that a tree planted in November, 1860, should have its roots shortened to eighteen inches in November, 1862 ; to twenty-four inches in 1864 ; to thirty inches in 1866 ; to three feet in 1868 ; and so on, leaving six inches biennially, till, say, a distance of six feet from the wall is reached in 1880. This border, six feet wide, ${ }^{1}$ will then be full of fibrous roots. It should never be dug or cropped, but annually have a surface dressing of manure about two inches in thickness; and, as I have before said, have a trench dug biennially eighteen inches deep, six feet from the wall, and the end of every protruding root cut off. If this method be followed, summer pinching to three leaves the first time, and to one leaf afterward, of the spurs on all the leading branches, may be practiced, and scarcely any winter pruning will be required.

In forming borders for wall pear trees on quince stocks biennially root-pruned, the soil should be well stirred with the fork to a depth of eighteen inches, and if it be poor a good dressing of rotten manure or leaf mold should be mixed with it. Pears on quince stocks are much better adapted for this mode of culture than those on pear stocks. If the latter be planted, the border, six feet wide, should have a

1 If the wall to which the trees are trained be twelve feet and upward in beight, the border should be eight and even ten feet in width. Wide and shallow fruit tree borders are much to be preferred to those that are deop and narrow. 
thick layer of concrete at bottom, to prevent the roots striking downward; or it would be good practice to place, eighteen inches deep, under each tree, a flat piece of stone, three feet in diameter-this would force the roots to take a horizontal direction, and facilitate the operation of root-pruning.

For fine specimens of wall pear trees grafted on the quince, I may refer to those on the west wall of the Royal Horticultural Society's Gardens at Chiswick. These are now about forty years old, and are pictures of health and fertility, thus at once settling the question respecting the early decay of pear trees grafted on the quince; for it has been often-very oftenurged as an objection to the use of the quince stock, that pears grafted on it are, although prolific, but very short-lived. I have seen trees in France more than fifty years old, and those above referred to may be adduced to confute this error.

\section{PEAR TREES TRAINED SINGLE AS VERTICAL CORDONS.}

The French gardeners have a curious yet interesting mode of training pears on the quince stock, about which a book was published in France a few years since. The system, I have recently learnt from some French cultivators, is now largely practiced in the south of France with the peach apricot. It is called training "en fuseau," or distaff training ; and is the most simple of all modes. A young tree, one year old from the bud, is planted, and every side shoot, as soon as it has made four leaves, has its top pinched off, leaving three. This is the first pinching early in June. These pinched shoots all put forth young 
shoots, which must be pinched to one leaf; and so on with all the young shoots during the summer, and the like practice every season. When the leading shoot has grown twelve inches, its top should be pinched off, and as soon as two or three break out at this point, all should be pinched in but one for the leader. A very compact distaff-like tree is thus formed.

For small gardens, where the cultivator wishes for a large collection of pears in a small place, this (which is, in fact, the cordon system applied to single stemmed trees) is to be recommended.

\section{A PEAR TREE HEDGE.}

A few days since, when visiting a friend at Fontenay aux Roses, near Paris, I was much struck with a hedge formed of pear trees on the quince stock. He smiled when he told me his method of cultivation and pruning, the latter being simply clipping his hedge in July, with the garden shears, ${ }^{1}$ and thinning out the spurs in winter, when they become crowded. A few days since (July, 1862), my firiend paid me a visit, and I inquired, with some interest, about-his pear tree hedge. He assured me that it was perfectly healthy, and generally gave him large crops of fruit. The sorts proper to form a hedge are Louise Bonne of Jersey, Beurré d'Amanlis, Beurré Hardy, Conśeiller de la Cour, Beurré d'Aremberg, Beurré Superfin, Délices de Jodoigne, Doyenné du Comice, Duchesse d'Angoulême, Prince Albert, and Vicar of Winkfield. These are all free growers on the quince stock, and if

1 An English cultivator would employ pruning scissors to shorten the shoots, and thus make his hedge look as if cared for. 
planted in a favorable soil and climate would soon form a fruitful hedge. They should be planted about thirty inches apart, and in masses, $i$. e., planting, say ten of each sort together. A hedge may be formed, varying more in its aspect by planting one or two trees of each sort in succession-this is a mere matter of taste. A pear tree hedge when in full bloom must have an agreeable look, and when full of fruit be very profitable.

\section{PYRAMIDS ON THE PEAR STOCK.}

There are some dry, warm, shallow soils, more particularly those resting on chalk or gravel, which are unfavorable to the pear on the quince stock: it is difficult to make them flourish, unless great care is taken in mulching the surface, and giving them abundance of water and liquid manure in summer. In such soils, pyramids on the pear stock may be cultivated with but little trouble.

To those who wish to train them as they should grow, one-year-old grafted plants may be selected, which may be managed as directed for young pyramids on the quince stock. If trees of mature growth are planted, they will require the treatment recommended for pyramids on the quince stock, as regards summer pinching. There is no occasion, however, to make a mound up to the junction of the graft with the stock, as the pear does not readily emit roots. Annual root-pruning is almost indispensable to pyramias on pear stocks in small gardens, and it will much facilitate this operation if each tree be planted. on a small mound, the roots are then so easily brought 
to the surface. This annual operation, which should be done in November, may be dispensed with in soils not rich, if the trees be lifted biennially in that month and replanted, merely pruning off the ends of any long roots. Annual surface manuring, as recommended for pyramids on the quince, is also necessary, if the trees be root-pruned or biennially removed.

Trees of the usual size and quality may be planted, and suffered to remain for two years undisturbed, unless the soil be rich and they make vigorous shoots (say eighteen inches in length) the first season after planting, in which case operations may then commence the first season. Thus, supposing a tree to be planted in November or December, it may remain untouched two years from that period; and then as early in autumn as possible a circumferential trench, twelve inches deep, should be dug, and every root cut with the knife and brought near to the surface, and the spade introduced under the trees, so as completely to intercept every perpendicular root.

The treddle spade used in this part of Hertfordshire is a very eligible instrument for this purpose, as the edge is steeled and very sharp. The following year, the third from planting, a trench may be again opened, at fifteen inches from the stem, so as not to injure the fibrous roots of the preceding summer's growth, and the knife and spade again used to cut all the spreading and perpendicular roots that are getting out of bounds. The fourth year the same operation may be repeated at eighteen inches from the stem; and in all subsequent root-pruning this distance from the stem must be kept. This will leave enough undisturbed 
earth round each tree to sustain as much fruit as ought to grow, for the object is to obtain a small prolific tree.

I find that in the course of years a perfect mass of fibrous roots is formed, which only requires the annual or biennial operation (the former if the tree be very vigorous) of a trench being dug, and the ball of earth heaved down to ascertain whether any large feeders are making their escape from it, and to cut them off. But it must be borne in mind that this circular mass of soil will in a few years be exhausted; to remedy which, I have had left round each tree, eighteen inches from the stem, a slight depression of the soil, or, in other words, the trench has not been quite filled in. This circular furrow I have had filled, in December and January, with fresh liquid night soil, covering it with a coat of burnt earth two inches thick, which has had a most excellent effect. Any other liquid manure would undoubtedly have been equally efficacious, but my soil was poor, and I thought it required strong manure. As it did not come in contact with the roots, no injury resulted from using such a powerful raw manure.

There is no absolute necessity for liquid manuring in winter, as common dung may be laid round each tree in autumn, and suffered to be washed in by the rains in winter, and drawn in by the worms. In mentioning liquid manure, I give the result of my own practice. The great end to attain seems (to use an agricultural phrase) to be able "to feed at home ;" that is, to give the mass of spongioles enough nutriment in a small space. A tree will then make shoots 
from eight to ten inches long in one season (for such ought to be the maximum of growth), and at the same time be able to produce abundance of blossombuds and fruit. On trees of many varieties, the former will be in too great abundance: removing a portion in early spring, cutting them out with a sharp knife, so as leave each fruit-spur about three inches apart, is excellent culture.

I have not yet mentioned the possibility of rootpruning fruit trees of twenty or thirty years' growth with advantage. Irregular amputation of the roots of too vigorous fruit trees is, I am aware, an old practice; but the regular, and annual or biennial pruning of them, so as to keep a tree full of youth and vigor in a stationary and prolific state, has not, that I am aware of, been recommended by any known author, although it may have been practiced. In urging its applicability to trees of twenty or thirty years' growth, I must recommend caution: the circular trench should not be nearer the stem of a standard tree than three feet, or, if it be a wall tree, four feet, and only two-thirds of the roots should be pruned the first season, leaving one-third to support the tree, so that it can not be blown on one side by the wind-and these, of course, must be left where they will best give this support. The following season - half the remaining roots may be cut, or, if the tree be inclined to vigor, all of them; but if it gives symptoms of being checked too much, they may, on the. contrary, remain undisturbed for one, or even two seasons. If, as is often the case in pear trees, the roots are nearly all perpendicular, the tree must be 
supported with stakes for one or two years after complete root-pruning.

The following extract from a letter recently received from C. Roach Smith, Esq., the archæologist, is interesting, as showing the prompt effects of rootpruning of trees:- "I have only been a horticulturist for three years; I took to two very beautiful old pear trees, which must have cost no end of nailing, cutting, and staking. On inquiry, I found that one (a Summer Bon Chrétien) had never produced more than one pear annually; the other, upon a north wall, had never given a single pear. I could get no aid from any one what to do with these trees, and no book then accessible helped me. I reflected on the natural habit of the pear tree, and, coming to the conclusion that the cause of barrenness was exuberance of roots, I resolved to cut them. Before the leaves had fallen, a friend sent me 'The Retired Gardener,' an old book, translated from the French. In it I found an account of some experiments made in England, which fortified me in the resolution I had taken. The first year the Summer Bon Chrétien ${ }^{1}$ produced nine fruit. I pruned the roots more closely, and this year (1859), in spite of the ungenial spring, I saved fifty-nine pears. The other tree yielded thirty-six, but of so vile a quality that I have re-grafted the tree. A large plum, treated in the same way, produced, the season after being root-pruned, 2000 fruit."

It will not, perhaps, be out of place here to enumerate a few of the advantages of systematic root-pruning and removing or lifting of pear, apple, and plum

\footnotetext{
1 This is one of our uldest varieties, and remarkable for being a very shy hearer
} 
treas, and of growing them as pyramidal trees and bushes.

1st. Their eligibility for small gardens, even the smallest.

2dly. The facility of thinning the blossom-buds, and in some varieties, such as Gansel's Bergamot and other shy-bearing sorts, of setting the blossoms, and of thinning and gathering the fruit.

3dly. Their making the gardener independent of the natural soil of his garden, as a few barrowfuls of rich mold and annual manure on the surface will support a tree for many, very many years, thus placing bad soils nearly on a level with those the most favorable.

4thly. The capability of removing trees of fifteen or twenty years' growth with as much facility as furniture. To tenants, this will, indeed, be a boon, for perhaps one of the greatest annoyances a tenant is subject to, is that of being obliged to leave behind him trees that he has nurtured with the utmost care.

My gray hairs tell me that I am not a young gardener, and yet I feel that in judicious root-pruning and annual manuring on the surface, so as to keep onr fruit trees full of short, well-ripened fruitful shoots, we are all inexperienced. At this moment I am reminded of a wall in a neighboring garden covered with peach and nectarine trees in the finest possible health.

For more than twenty years a healthy peach tree was never seen in this garden, as the subsoil is a cold white clay, full of chalk-stones. This happy change has been brought about by biennially pruning the roots of the trees early in autumn, as soon as the fruit is gathered; in some cases lifting the trees and sup- 
plying their roots with a dressing of leaf-mold, sand, and rotten manure, equal parts. Powdered charcoal, or the ashes of burnt turf and rotten manure, also make an excellent root-dressing for cold heary soils; but if the soil be dry and poor, and unfavorable to the peach and nectarine, loam and rotten manure is the best dressing for the roots, and also for the surface.

\section{PLANTING AND AFTER MANAGEMENT.}

Pyramidal pear trees of from three to five years old on the quince stock, root-pruned, and full of blossombuds, may now' be purchased. Trees of this description should, if possible, be planted before Christmas; but if the soil be very tenacious, the holes may be opened in the autumn, and the trees planted in February; the soil will be mellowed and benefited by the frosts of winter. ${ }^{1}$

Pear trees grafted on the quince stock offer a curious anomaly, for if they are removed quite late in spring-say toward the end of March, when their blossom-buds are just on the point of bursting-they will bear a fine and often an abundant crop of fruit. This is sometimes owing to the blossoms being retarded, and thus escaping the spring frosts; but it has so often occurred here when no frosts have visited us that I notice it-in fact, no trees bear late removal so well as pears on quince stocks.

1 The roots of pear trees on the quince stock, and, indeed, of all root-prnned trees are very fibrous. In planting, it is good practice to give each tree two shovelfuls of fine earth or mold rather dry-to place it on the roots and shake the tree, so that the mold is well mixed with the mass of fibrous roots. Befure the soil is all filled in, three or four gallons of water should be poured in, so as to wash the earth into every crevice. The roots should not be crammed into a small holo. A tree, with its roots 18 inches in diameter, will require 8 hole $2 \frac{1}{8}$ feet in diameter, and so on in proportion. 
In planting pear trees on the quince stock, it is quite necessary that the stock should be covered up to its junction with the graft. This joining of the graft to the stock is generally very evident, even to the most ignorant in gardening matters; it usually assumes the form as given in Fig. 11, $a$.

If the soil be not excessively wet, the tree may be placed in a hole, say three feet in diameter and eighteen inches deep, in the usual way, so that the upper raots are slightly above the level of the surface, as the tree will always settle down two or three inches the first season after planting. Some of the light compost recommended in page 19 should be filled in, and the tree well shaken, so that it is thoroughly mingled with its roots. The compost must then be trodden down;

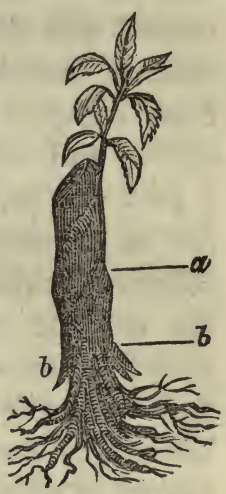

Frg. 11. and so far the planting is finished. The earth should then be placed round the stem, and formed into a mound, which should cover the stock up to, but not above, the junction of the graft with the stock, in order to encourage it to emit roots into the surface soil, and to keep it (the stock) from becoming hard and "bark-bound."

To make this emission of roots more certain, the stem may be tongued, as usual in layering-i.e., the bark must be cut through upward from the root, and a slip about one inch in length raised (see Fig. 11, $b$, $b$, which are the raised pieces of bark); and these raised pieces of bark must be kept open by inserting 
a piece of broken flower-pot or slate. Several of these tongues may be made, and by the end of the first year after planting every incision will have emitted roots; the stock, owing to its being kept constantly moist, will swell and keep pace with the graft, and the tree will flourish and remain healthy. As the mound will subside by the heavy rains of winter, presuming that the trees have been planted in autumn, fresh cornpost of the same nature must be added in spring, and every succeeding autumn. A quarter of a peck of soot, strewed on the surface in a circle three feet in diameter round each tree in March, is an excellent stimulant. The great object in the culture of the pear on the quince stock is to encourage the growth of its very fibrous roots at the surface, so that they may feel the full influence of the sun and air. The slight mounds recommended may be made ornamental if required, by placing pieces of rock or flint on them, which will also prevent the birds scratching at them for worms; but the stones selected must not be very large and heary - they should be about the size and weight of a brick. In light friable soils, the mounds may be from three to four inches above the surface of the surrounding soil ; in heavy retentive wet soils, from six to eight inches will not be found too high.

In soils of a light dry nature the pear on the quince requires careful culture. I therefore recommend the surface round the tree to be covered, during June, July, and August with short litter, or manure, and to give the trees once a week, in dry weather, a drenching with guano water (about one pound to ten gal- 
lons), which must be well stirred before it is used. Each tree should have ten gallons poured gradually into the soil; by this method the finest fruit may be produced; and as it is very probable that, ere many years elapse, we shall have exhibitions of pears, this will be the mode to procure fine specimens to show for prizes. Our oldest gardening authors have said, that "pears ingrafted on the quince stock give the fairest fruit;" and they are correct. It has been asserted that the fruit is liable to be gritty and deficient in flavor. I can only say, that from my trees, growing on a cold clayey soil, I have tasted fruit of Marie Louise, Louise Bonne of Jersey, and others, all that could be wished for in size and flavor.

In the course of my experience, and since the above recommendation to plant on mounds was written, I have found it good practice in very dry soils to plant pear trees on the quince stock with the junction of the graft just level with the surface, so as not to require mounds round their stems. The first season they should have some manure on the surface, laid in a circle round the stem; and the second year a shallow basin, two feet in diameter and four inches deep, should be dug round the stem, and filled with some manure about half rotten. This basin thus filled will keep moist even in the most dry and hot weather, and will become full of fibrous roots. This is also an excellent method of renovating pear trees that have exhausted themselves by bearing too abundantly, or that appear unhealthy by their leaves turning yellow. In such cases, when the trees are of advanced growth, a basin of the same depth, but three or more feet in diameter, 
should be formed and filled with manure: in all cases for this purpose this should be but slightly decomposed.

\section{BUSH PEAR TREES FOR A MARKET GARDEN.}

There are many favorable sunny spots which the amateur gardener may turn to profit accompanied by pleasure, simply by planting bush pear trees grafted on the quince stock. The plantation should be a sort of nursery, and for this purpose they should be planted in rows, three feet row from row, and three feet apart in the rows; a piece of ground planted after this method will contain 4,840 trees per imperial acre.

By pinching every shoot to three leaves all the summer, the trees form compact fruitful bushes; this constant summer pinching has a remarkable effect in moderating the vigor of fruit trees. They will commence to bear the second year after planting, and if each tree give but ten or twelve fruit, one acre will produce a large quantity. They may be suffered to remain at the above distance unroot-pruned, and unremoved for seven, eight, or ten years; and then, as they will nearly or quite touch each other, every alternate tree should be removed, and another plantation formed. The removal of the trees should be done carefully, so that those left will stand four feet and a half apart and in quincunx order, thus, ${ }_{*^{*}}^{*} *^{*}$. This may be done as follows:-Presuming the first row to consist of ten trees, begin at the first row by removing the 1st, 3d, 5th, 7th, and 9 th trees; in the second row, remove the $2 \mathrm{~d}, 4 \mathrm{th}, 6 \mathrm{th}, 8 \mathrm{th}$, and $10 \mathrm{th}$; in the third row, again 1st, $3 \mathrm{~d}, 5$ th, 7 th, and 9 th trees, and so on 
with all, and through all the rows however long; at this distance they may remain for fourteen, eighteen, or twenty years. At the end of one of these periods, every alternate row of trees must be removed, leaving the permanent trees six feet apart: the periods of removal must, to a certain extent, depend upon the nature of the soil; if this be of high fertility, the removal of the trees must be commenced at the earlier period. It may sound strangely to the routine gardener to advise the removal of fruit trees when twenty years old; but I say this advisedly, for the trees in a plantation of Louise Bonne pears on the quince stock, planted here twenty years since, in rows five feet apart, were recently removed and have succeeded well, commencing to bear fine crops the second season after being transplanted. When pyramidal trees from ten to twenty years old are removed, their branches should all be shortened to at least one-half their length. Although these trees were planted only five feet apart and have grown well, they did not-and those left unremoved do not-touch each other; this is, of course, owing to their young shoots having been pinched in every summer for so many seasons.

From closely observing these trees for many years, and even to-day (July 20th, 1864), upon measuring the shoots of the unremoved trees, and finding they do not meet by at least fifteen inches, I have based the idea conveyed by the heading of these paragraphs, p. 54. It may be-asked, why not plant pyramids, which are handsome and productive? Experience furnishes me with a reply: When my 2,000 pyranids of Louise Bonne pears commenced to bear their large 
crops of fruit, I found so many displaced by the wind that supporting them with stakes became expensive and troublesome; I therefore recommend all those, who wish to make their pear-tree plantations profitable as well as pleasurable, to plant bush trees. ${ }^{1}$ In sheltered gardens the amateur may without hesitation continue to plant pyramids, for no description of fruit tree can be more interesting; but when profit is to be attached to cultivation, and fruit trees cultivated by the acre, the bush form must be adhered to. The varieties best adapted to this mode of culture are, first and best, Louise Bonne of Jersey, Fondante d'Automne, Beurré d'A remberg, Beurré Superfin, Williams's Bon Chrétien, Beurré Bachelier, Winter Nelis, and Bergamotte d'Esperen. If more robust growing sorts are planted, such as Beurré Diel, Beurré d'Amanlis, Beurré Hardy, and some others, the plantation should be commenced with rows four feet apart, and the trees four feet apart in the rows. The ground occupied by the plantation should be stirred with the Parkes' steel fork every season, in February or March, but not deeper than from four to five inches, and the weeds carefully turned down. In the summer the weeds must be kept under by hoeing, which will keep the surface loose and promote the health of the trees; without this stirring with the fork in early spring, the soil would become too hard during the summer for hoeing with facility.

\section{GATHERING THE FRUIT.}

The fruit of pears, more particularly those on

1 These may be with advantuge a sort of hybrid bush tree, partaking a little of the pyrumil, and allowed to grow to a height of four or tive feet. 
quince stocks, should not be suffered to ripen on the tree; the summer and autumn varieties should be gathered before they are quite ripe, and left to ripen in the fruit room. ${ }^{1}$ The late pears should be gathered before the leaves take their autumnal tints ; if suffered to remain too long on the trees, they frequently never ripen, but continue hard till they rot. In most seasons, the first and second week in October is a good time; but much depends on soil and climate. The following passage from that very excellent work, Downing's "Fruit Trees of America," is appropriate to this subject :-

"The pear is a peculiar fruit in one respect, which should always be kept in mind-viz., that most varieties are much finer in flavor if picked from the tree, and ripened in the house, than if allowed to become fully matured on the tree. There are a few exceptions to this rule, but they are very few. And, on the other hand, we know a great many varieties which are only second or third rate when ripened on the tree, but possess the highest and richest flavor if gathered at the proper time, and allowed to mature in the house. This proper season is easily known, first by the ripening of a few full-grown but wormeaten specimens, which fall soonest from the tree; and, secondly, by the change of color, and the readiness of the stalk to part from its branch on gently raising the fruit. The fruit should then be gathered -or so much of the crop as appears sufficiently matured-and spread out on shelves in the fruit-room,

3 Pears that ripen in September and October should not be gathered all at one time, but at intervals of a w(ek or st), making, say, three gatlurings; their season is thus inuch prolonged. 
or upon the floor of the garret. Here it will gradually assume its full color and become deliciously melting and luscious. Many sorts, which, if suffered to ripen in the sun and open air, are rather dry, when ripened within doors, are most abundantly melting and juicy. They will also last for a considerably longer period if ripened in this way, maturing gradually as wanted for use, and being thus beyond the risk of loss or injury by violent storms or high winds.

"Winter dessert pears should be allowed to hang on the tree as long as possible, till the nights become frosty. ${ }^{1}$ They should then be wrapped separately in paper, packed in kegs, barrels, or small boxes, and placed in a cool, dry room, free from frost. Some varieties, as the Beurré d'Aremberg, will ripen finely with no other care than placing them in barrels in the cellar, like apples. But most kinds of the finer winter dessert pears should be brought into a warm apartment for a couple of weeks before their usual season of maturity. They should be kept covered, to prevent shrivelling. Many sorts, that are comparatively tough if ripened in a cold apartment, become very melting, buttery, and juicy, when allowed to mature in a room kept at the temperature of 60 or 70 degrees."

The following is from Mr. Glass's "Gardening Book," as given in the Gardener's Chronicle:-

HOW TO STORE WINTER PEARS IN SMALL QUANTITIES.

"Get some unglazed jars-garden pots will do;

1 I feel compelled to differ from Mr. D. in this respect; for in the autumn of 1855 I suffered many pears to hang on the trees till the end of October, and they never ripened. I helieve the first week in October to be the best period to gather winter pears in. 
make them perfectly clean, if they have ever been used. The best way is to half burn or bake them over again.

"Gather your pears very carefully, so as not to rnb off the bloom or break the stalk. On no account knock them about so as to bruise them. Put them on a dry sweet shelf, to sweat. When the sweating is over, rub them dry with a soft cloth, as tenderly as if you were dry-rubbing a baby.

"As soon as they are quite dry, put them, one over the other, into the jars or garden pots, without any sort of packing; close up the mouth of the jar loosely, or of the garden-pot, by whelming the pan or placing a piece of slate over it, and stow them away in a darkish closet where they cannot get the frost.

"Open the jars now and then, to see how they are getting on.

"Do not put more than one sort in the same jar, if you can help it. Mind-the warmer they are kept, the faster they will ripen."

\section{KEEPING PEARS IN A GREENHOUSE.}

I have but very recently found that pears may be kept in a greenhouse, in great perfection, all the winter.

The greenhouse in which my experiment has been tried is a lean-to house with a S. W. aspect, twelve feet wide, with a path in the centre, a bench in front, of common slates laid on wooden bars, and a stage at back, full of camellias. My pears have been laid on the front bench, the glass over them shaded till the end of November, the house ventilated, and the 
camellias watered just as 'if the pears were not there. In severe frosts, the temperature was kept just above freezing. The autumn pears under this treatment ripened slowly, and were of excellent flavor. The late pears kept till April; but then, owing to the power of the sun, the air of the house became too warm and dry, and they shrivelled. I should therefore recommend winter pears to be kept in the greenhouse in covered pots or jars (I now use large clean flower-pots with wooden covers), placing them in early in December.

Mr. Tillery, of the Wellbeck Gardens, keeps his choice pears and apples in boxes of bran with great success. The bran, before it is used, should be thoroughly dried and sifted, so as to take from it all the small particles of meal. With this treatment pears and apples may be placed in it as soon as they are gathered. The boxes should be quite shallow, so as to admit of only one layer of fruit, which should be covered with the bran, and no lids placed on the boxes. The bran is apt to become musty.

PYRAMTDAL APPLE TREES ON THE PARADISE APPLE STOCK.

Apples as pyramids on the Paradise stock are objects of great beauty and utility. This stock, like the quince, is remarkable for its tendency to emit numerous fibrous roots near the surface, and for contracting the growth of the graft, causing it to become fruitful at a very early stage. On the Continent there are two varieties of the apple under this denomination-viz., the Doucin and the Pomme de Paradis: these are 
called Paradise stocks in England, but on the Continent the first and last are used for distinct purposesthe first for pyramids, the latter for dwarf bushes.

The Doucin stock is, I am inclined to think, the same as that called "Dutch Creeper," or "Dutch Paradise," by Miller, in his Dictionary, folio edition of 1759. It puts forth abundance of fibrous roots near the surface of the soil, and is not inclined to root deeply into it like the crab. Apples grafted on this stock are more vigorous than when grafted on the true Paradise stock, and less so than those on the crab ; it is, therefore, well adapted for garden trees, for they are easily lifted, their roots thus kept to the surface, and the tree consequently kept free from canker. There is another surface-rooting apple, also well adapted for stocks-the Burr Knot. This, like the Doucin, will strike root, if stout cuttings, two or three years old, are planted two-thirds of their length in a moist soil : it is a large, handsome, and very good culinary apple. At Ware Park, in Hertfordshire, this is called Byde's Walking-stick Apple, owing to Mr. Byde, the former proprietor of the place, often planting branches with his own hand, which soon formed nice bearing trees.

Among apples raised from seed, some will occasionally be found with this surface-rooting nature ; and this is, I suspect, the reason why the Doucin stock, under the name of the Paradise, common in the English nurseries, differs from the sorts used as Doucins in France: there are also two or three varieties cultivated there.

About forty years since, I raised a large number of 
apples from the pips of the Golden Pippin, Golden Reinette, Ribston Pippin, and other esteemed sorts. These, in course of time, all bore fruit, but, as not one was found superior to its parent, I did not cultivate them. Why I mention this is, that among my seedlings were several that put out roots near the surface, and the cuttings of which struck root. It is only within these few years that I have had my attention drawn to two of these, one of which has very broad leaves, and a most healthy and vigorous habit; the other, a habit equally vigorous, but with a great tendency to form fruit-spurs. The former I have named the Broad-leaved Paradise, the latter, the Nonesuch Paradise; they are likely to form a revolution in apple culture, as the varieties of apples grafted on them form such healthy and fruitful trees.

The Pomme de Paradis seems identical with the "dwarf apple of Armenia," referred to in the "Journal of the Horticultural Society," Part 2, Vol. 3, page 115. It is exceedingly dwarf in its habit, and too tender for this climate, unless in very warm and dry soils. Out of 2,000 imported in 1845 , more than half died the first season, and two-thirds of the remainder the following. They were planted in fine fertile loam, favorable to the growth of apples, and on which the Doucin, planted the same season, grew with the greatest vigor. The same result attended an importation of 2,000 in 1846 . I have now potted some plants, and owing, as I suppose, to the roots being warmed through the pots by exposure to the sun, they seem inclined to make very nice little fruitful bushes-in fact, real miniature apple trees, bearing 
fruit when only nine inches in height. My trees are in eight-inch pots ; but, to have healthy fertile trees, I should recommend them to be gradually shifted into fifteen-inch pots. The citizen may thus have his apple orchard on the leads of his house.

The English Paradise stock, much like the Doucin, and those above-mentioned as my seedlings, are most deserving of our attention as stocks for forming fruitful pyramids, the culture of which is very simple. Grafted trees of one, two, or three years' growth, with straight leading stems, well furnished with buds and branches to the junction with the stock, should be planted. No manure should be placed to their roots, but some light friable mould should be shaken into them, the earth filled in, trodden down, and two or three shovelfuls of half-rotted manure laid on the surface round each tree. This surface-dressing may be given with advantage every succeding autumn. If the soil be very wet and retentive, it will be better to plant the trees in small mounds; and if symptoms of canker make their appearance, their roots should be examined annually in the autumn, as recommended in root-pruning of pears on the quince stock, introducing the spade directly under the roots, so as to prevent any entering deeply into the soil, and bringing all as nearly to the surface as possible, filling in the trench with light friable compost; or the tree may be lifted and replanted, which will be found more efficient. I firmly believe that canker may be entirely prevented by this annual attention to the roots.

If, therefore, the soil be unfavorable, and apt to induce a too vigorous growth in apple trees, followed by 
canker, the roots should be annually root-pruned, or the trees lifted-i. e., taken up and replanted. If, however, the trees make shoots of only moderate vigor, and are healthy and fruitful, their roots may remain undisturbed; and pinching their shoots in summer, as directed for pyramidal pears, page 9, and training them in a proper direction, is all that they will want. Pyramids on the Paradise stock may be planted four feet apart in confined gardens; five feet will give them abundance of room; but if, owing to the soil being of extra fertility, they are found to require more, the trees, if they have been root-pruned, may be removed almost without receiving a check, even if they are twenty years old. This is a great comfort to the amateur gardener, who amuses himself with improving his garden; for how often does a favorite fruit tree, which cannot be removed, prevent some projected improvement!

Apples differ greatly in their habits of growth; some are inclined to grow close and compact, like a cypress-these are the proper sorts for pyramids; others, horizontally and crooked-these should be grown as bushes; others, again, are slender and thin in their growth, so that, to form a good pyramid of these slender-growing varieties, it is necessary to begin the first year with a young tree, and to pinch the leader as soon as it is six inches long. If by any neglect the lower part of the pyramid be not furnished with shoots, but have dormant buds, or buds with only two or three leaves attached, a notch must be cut, about half an inch in width, just above the bud from which a shoot is required. This notch must be cut 
through the outer and inner bark, and alburnum, or first layer of wood; and if the shoot or stem be young - say from two to four inches in girth-it may be cut round half its circumference. If this be done in spring or summer, the following season a shoot will generally make its appearance; sometimes even the first season, if the stem or branch be notched early in spring. This method of producing shoots from dormant buds may be applied with advantage to all kinds of fruit trees, except the peach and nectarine, which are not often inclined to break from a dormant bud.

Varieties of apples inclined to be compact and close in their growth form very handsome pyramids; but they are apt to be unfruitful, as air enough is not admitted to the interior of the tree. This may be easily avoided, by bringing the lateral shoots down to a horizontal position for a year or two, and fastening the end of each shoot to a stake; an open pyramidal shape will thus be attained, which the tree will keep. Other varieties put forth their laterals horizontally, and some are even pendulous. The leading perpendicular shoot of varieties of this description must be supported by a stake till the tree is of mature age. Iron rods, about the size of small curtain-rods, are the most eligible: these, if painted with coal-tar and lime, sifted and mixed with it to the consistence of very thick paint, put on boiling hot, will last a great many years.

Apple trees in eonfined gardens near large towns are often infested with "American blight," aphis lanigera: this makes its appearance on the trees generally towards the middle of summer, like patches of cotton wool. There are many remedies given for 
this pest; the most efficacious I have yet found is soft soap dissolved in soft water, two pounds to the gallon, or the Gishurst Compound, sold by Price's Candle Company, one pound to the gallon, and applied with an old painter's brush. Many remedies, such as train oil, spirits of tar, \&c., are apt to injure the trees: it must be recollected that soft soap will turn the leaves brown-in fact, kill them; but it need not be applied to them, as the aphis generally fixes itself on the branches.

Here let me impress upon the lover of his garden, living anywhere within reach of smoke, the necessity of nsing the syringe: its efficacy is not half appreciated by gardening amateurs. As soon as the leaves of his fruit trees are fully expanded, every morning and every evening, in dry weather, should the attentive gardener dash on the water with an unsparing handnot with a plaything, but with the perforated common syringe, such as a practical gardener would use, capable of pouring a sharp stream on the plant, and of dislodging all the dust or soot that may have accumulated in twelve hours. For apple and pear trees in pots, or in small city gardens, this syringing is absolutely necessary.

Pinching the shoots of pyramidal apple trees, and, indeed, exactly the same method of managing the trees as given for pyramidal pears on the quince stock, may be followed with a certainty of success; and the proprietor of a very small garden may thus raise apple trees which will be sure to give him much gratification. To have fine fruit, the clusters should be thinned in June ; and small trees should not be orerburdened, 
for they are often inclined, like young pear trees on the quince stock, to bear too many fruit when in a very young state; the constitution of the tree then receives a shock which it will take two or three seasons to recover. For varieties with large fruit, one on each fruit-bearing spur will be enough; if a small sort, from two to three will be sufficient.

There are so many really good apples that it is difficult to make a selection : the following sorts will not disappoint the planter; but fifty varieties in addition, quite equal in quality, could be selected.

Twenty dessert apples, ripening from July to June, placed in the order of their ripening:-
1. White Joanneting*
2. Early Red Margaret
3. Red Astrachan
4. Early Strawberry
5. Irish Peach*
6. Summer Golden Pippin
7. Kerry Pippin*
8. Margil
9. Ribston Pippin*
10. Cox's Orange Pippin*
11. Mannington's Pearmain
12. Golden Drop (Coe's)*
13. Ashmeal's Kernel*
14. Nonpareil, old
15. Reinette Van Mona*
16. Syke House Russet
17. Keddleston Pippin
18. Golden Harvey
19. Winter Peach $A_{\text {Iple }}$
20. Sturmer Pippin*

Twenty kitchen apples, fit for use from July to June :-
1. Keswick Codlin*
2. Large Yellow Bough
3. Hawthornden*
4. Cellini
5. King of the Pippins
6. Blenheim Pippin*
7. Calville Blanche
8. New Hawthornden
9. Striped Beefing*
10. Waltham Abbey Seedling

11. Herefordshire Pearmain*
12. Winter Pearmain
13. Bedfordshire Foundling*
14. Greaves's Pippin
15. Dumelow's Seedling*
16. Forge Apple
17. Rymer
15. Baster's Pearmain*
19. St. Saureur*
20. Gooseberry Apple*

APPLES AS BUSHES ON THE PARADISE STOCK.

There are some varieties of apples that do not form, even with care, well-shaped pyramids; such sorts may be cultivated as bushes when grafted on the Paradise 
stock, and are then excellently well adapted for small gardens. I have, indeed, reason to think that a great change may be brought about in suburban fruit culture by these bush trees. I have shown, in pp. 17 and 18 , how bush pears on quince stocks may be cultivated. Pears are, however, a luxury: apples and plums are necessaries to the families of countless thousands living near London. Apple bushes, always very pretty and productive trees, may be planted three feet apart, row from row, and three feet apart in the rows. If two or three years old when planted, they will begin to bear even the first season after planting. They should be kept from the attacks of the green aphis in summer by dressing the young shoots with the quassia mixture, given in a note to $\mathrm{p}$. 89 , and from the woolly aphis by Gishurst compound, mentioned in page 66 . The principal feature in this culture is summer pinching, which must be regularly attended to, from early in June till the end of August: this is done by pinching or cutting off the end of every shoot as soon as it has made five or six leaves, leaving from three to four full-sized ones. Some varieties of the apple have their leaves very thickly placed on the shoots; with them it is better not to count the leaves, but to leave the shoots from three and a half to four inches in length. If the soil be rich, and the trees inclined to grow too vigorously, they may be removed biennially, as recommended for bush pears, by digging a circular trench one foot from the stem of the tree, and then introducing the spade under its roots, heaving it up so as to detach them all from the soil, and then filling in the earth dug from 
the trench and treading it gently on to the roots. The following sorts are well adapted for this bush culture, but the upright varieties recommended for pyramids form nice compact bushes. ${ }^{2}$

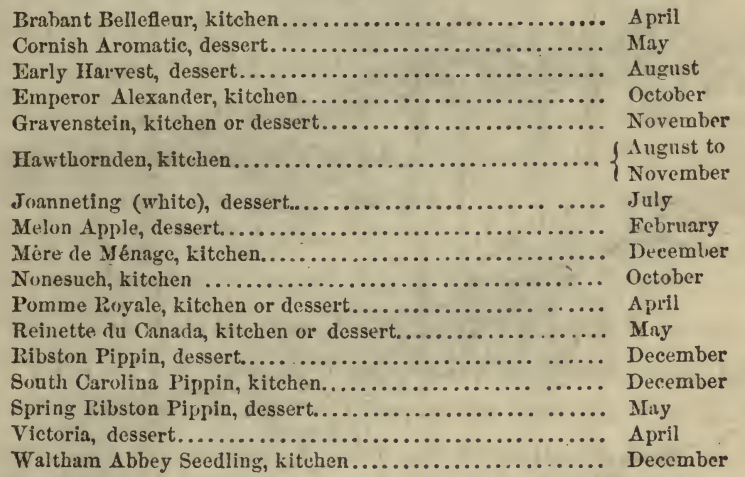

There is no mode of apple culture more interesting than bush culture. On the next page I annex a sketch of a plantation of Cox's Orange Pippin (Fig. 12), of one hundred trees; they were planted in the spring of 1862. They bore a fine crop in 1863 of most beautiful fruit, and in 1864 gave a crop almost too abundant.

\section{APPLES A\& BUSHES FOR MARKET GARDENS.}

Our market gardeners, as a rule, are- very deficient in their knowledge of fruit-tree culture, and they have much to learn. The usual practice with them is to plant standard or half standard trees in rows, some twenty or thirty feet apart, and between them goose-

1 These dwarf bushes are liable to be gnawed by rabbits and hares in exposed gardens. The best of all preventives is to paint them with soot and milk, well mixed; or make a fence with galvanized wire netting, round the garden in which they are planted. 
berry and currant trees. The ground is dug between the trees in spring deeply, and often carelessly. Nothing can be more barbarous, for the ground is so

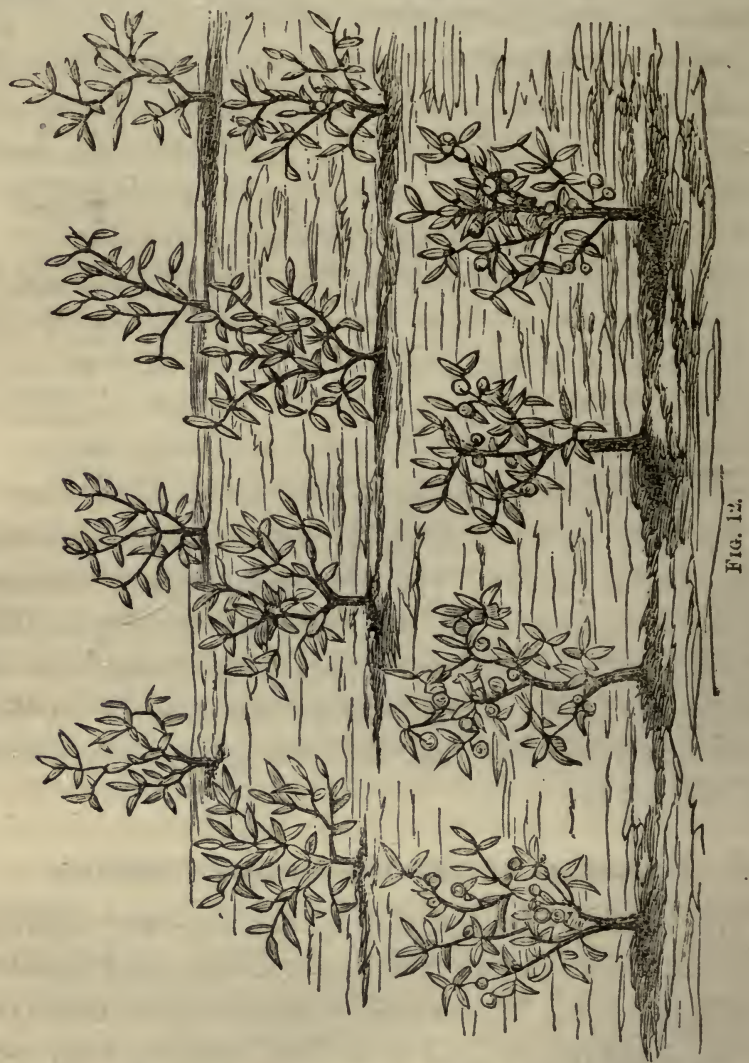

shaded that no surface roots can have the benefit of air and the heat of the sun; and if by any chance they could come to the surface, they are, as a matter of course, destroyed by the spade. It is true that in 
some of the rich market gardens near London large quantities of fruit are grown in spite of the uncouth treatment the trees receive, but this does not alter the case.

In a well-ordered fruit garden, every kind of fruit should have its department, and instead of seeing, as in Kent, a row of trees of all sorts, mixed in the most heterogeneous manner, no mixture of species should be allowed; every kind should have its allotmentapples on the Paradise stock, ditto on the crab stock, pears on the quince stock, the same on the pear stock. Morello cherries as pyramids on the Mahaleb stockthe best of all methods for their culture-and the various kinds of Duke cherries on the same kind of stock. Heart and Bigarreau cherries on the common cherry stock, plums as bushes, pyramids, or half standards, should all be separated, and not planted higgledy-piggledy, as they have been and are now. The sound-headed market gardener will, when his mind is turned to improved fruit-tree culture, see all this, and make his fruit garden a pattern of order.

I have been led into these remarks on market garden fruit-tree culture by my own experience, and especially into a consideration of the great improvement that may be made in the culture of apples on the English Paradise stock. On referring to p. 69, the reader will find that $I$ allude to my plantation of Cox's Orange Pippin apple trees on the Paradise stock (see Fig. 12); these trees will this season (1864), the third of their growth in their present quarters, and the fourth of their age, give an average of a quarter of a peck from each tree, so that we might 
have from 4,840 trees, growing on one acre of ground, 302 bushels of fine apples, worth 5s. per bushel, or $£ 75$. In 1866, the trees then averaging half-a-peck each, would double this sum, and make an acre of apple trees a very agreeable and eligible investment. The kinds likely to sell best in the xnarkets, and which are most productive, are the following:-Cox's Orange Pippin, Reinette Van Mons, Ribston Pippin, Sturmer Pippin, Scarlet Nonpareil, and Dutch Mignonne; these are dessert apples. The following are valuable kitchen apples, and abundant bearers:Hawthornden, New Hawthornden, Small's Admirable, Cox's Pomona, Keswick Codlin, Dumelow's Seedling, Lord Suffield, Norfolk Bearer, Duchess of Oldenburg, and Forge Apple. Such large varieties as Bedfordshire Foundling, Blenheim Orange, and Warner's King, should have more space, and be planted four feet apart, and be thinned out by remo. val, as recommended for pear trees, three feet apart, for which see p. 54. The proper method of planting and managing these bush apple trees is exactly that recommended for bush pear trees on quince stocks.

It may be by some made a question of expense, for although the return must be large and profitable, the purchase of nearly 5,000 apple trees would involve a large outlay. To this I reply-first, that stocks costing only a small sum per 1,000 may be planted and grafted where the trees are to grow permanently; and, second, that a large demand which my method of planting would create will also create a cheap supply. The preparation of an acre of ground should be as follows:-It should previous to planting, be forked 
over to a depth of twenty inches (if very poor and exhausted, from thirty to forty tons of manure may be forked in)-not more, as trees such as I have recommended, viz., pears on the quince stock and apples on the English Paradise stock, do not root deeply-this ought to cost $£ 613 \mathrm{~s}$. $4 \mathrm{~d}$. The annual expenses are forking the surface in spring, $£ 1$ ss. 8 d., and hoeing the ground, say four times during the summer, $£ 14$ s. I give the amounts paid here for such work. Then comes the summer pinching of the shoots by a lightfingered active youth, and this may, at a guess, be put down at $£ 1$, making the aggregate annual expenses $£ 310$ s. 8 d., or, say $\& 4$ per acre. The large return will amply afford this outlay, even adding, as we ought to do, the interest on capital, and rent.

It will be seen that what I propose is in reality a Nursery Orchard which may be made to furnish fruit and trees for a considerable number of years. To fully comprehend this, we must suppose a rood of ground planted, as I have described, with 1,210 bush apple trees. In the course of eight or ten years, half of these, or 605 , may be removed to a fresh plantation, in which they may be planted 6 feet apart; they will at once occupy half an acre of ground. At the end of sixteen or eighteen years, every alternate row of trees in the first plantation-the rood-will require to be removed, which will give 302 trees to be planted, 6 feet apart, leaving 303 in the original rood. The 1,210 trees will, by this time, occupy one acre of ground at 6 feet apart. With proper summer pruning or pinching, they will not require any further change, but continue to grow and bear fruit as long 
as they are properly cultivated." The great advantage reaped by the planter is the constant productiveness of his trees; from the second year after planting they will be always "paying their way."

The unprejudiced fruit cultivator will quickly find out the great advantage of my mode of apple and pear cultivation.

In the usual old-fashioned mode, Standard apple trees are planted in orchards at 20 feet apart, or 108 trees to the acre; if the soil be good and the trees properly planted, and the planter a healthy, middleaged man, he may hope, at the end of his threescore and ten, to see his trees commencing to bear, and may die with the reflection that he has left a valuable orchard as a legacy to his children, but has not had much enjoyment of it during his life. Now, although, like most fathers, I have a strong wish to benefit my children, I hold the idea that one ought also to think of one's own gratification; and so I have planted, and recommend the planting of such as will give me some satisfaction, yet leave a fertile legacy to my children.

A French pomologist, who paid me a visit last year, said, "Ah! now I find an Englishman planting for himself as well as for his children :" and went on to say that he was struck by seeing in England so many Standard trees in market gardens, the planters of which could have derived but small benefit from them; and the apparent ignorance of fruit gardening as a lucrative occupation. This he, in fact, imputed to our climate, which, Frenchman-like, he thought totally unfit for fruit culture in the open air, yet felt 
much surprised to see here the produce of a well-cultivated English fruit garden, in a climate not nearly so favorable as the valley of the Thames.

I have only to add that, besides my plantation of Cox's Orange Pippin, I have another of upwards of 400 trees, which has now been in existence upwards of ten years, so that I am not theorizing, but deducing facts from a sound basis.

\section{APPLES AS SINGLE LATERAL CORDONS.}

The French gardeners often train an apple tree " en cordon horizontale," as an edging to the borders in their kitchen gardens, after the following mode:-A

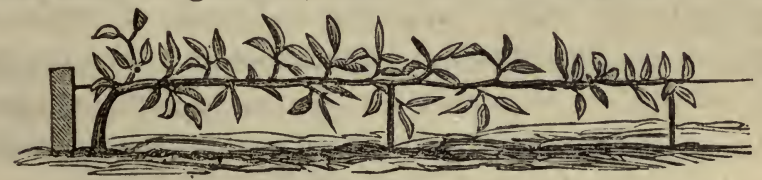

Fig. 18.

tree grafted on the Paradise or Doucin stock, with a single shoot, is planted in a sloping position, and the shoot trained along a wire, about ten or twelve inches from the surface. (Fig. 13.)

To carry out this method of training, oak posts, about three inches in diameter and two feet in length, should be sharpened at one end and driven into the ground, so that they stand one foot above the surface; they may be from thirty to forty yards distant from each other.

From these a piece of galvanized or common iron wire-if the latter, it should be painted-about the thickness of whipcord, should be strained, and supported nine inches from the ground, at intervals of six 
feet, by iron pins eighteen inches long, the size of a small curtain-rod, or smaller, flattened at the top and pierced with a hole, to allow the wire to pass through; these should be stuck into the ground, so as to stand on a level with the straining-posts. The trees should be planted six feet apart, and when the top of one tree reaches to another the young shoot may be grafted on to the base of the next, so as to form a continuous cordon. This is best done by merely taking off a slip of bark, two inches long, from the under part of the young shoot, and a corresponding piece of bark from the upper part of the stem of the tree to which it is to be united, so that they fit tolerably well. They should then be firmly bound with bast, and a bunch of moss-a handful-as firmly bound over the union; the binding as well as the moss may remain on till the autumn. The trees do not grow so rapidly as common grafts, so that the ligatures will not cut into the bark.

Every side shoot of these cordons should be rigorously pinched into three leaves all the summer, and the fruit, from being near the earth, and thus profiting largely by radiation, will be very fine.

The double lateral cordon, see Fig. 14, which is a great improvement on the French single cordon, requires the same training, pinching-in, and management.

The great change in fruit culture that may be brought about by training these double lateral cordons under glass ridges is obvious enough. The figure (15) will give some faint idea of the advantages of this new system of culture-they are endless'; for not only can peaches, nectarines, apricots, plums, apples, and pears 
be rescued from spring frosts, but their fruit be ripened in great perfection. There is no doubt but that in some of our cold and cloudy places in the north of England and Scotland, where even the Ribston Pippin will not ripen, it may be brought to perfection under the glass fruit ridge.

The figure (Fig. 15) gives but one tree trained to one wire; two rows of wire may, however, be trained under one ridge, which should be three feet wide at base, and the wires ten inches asunder. It is quite possible that this method of training to galvanized wires may, in some situations, be better adapted to vine culture than allowing the vines to rest on slates or tiles.

I now, by permission, copy the description of my new glass fruit ridge from my article in the Gardener's Chronicle for April 8, 1865, from which I have also derived the plate kindly lent to me:-

"There are no cross-bars, but merely a frame three feet wide at the base. On the top bar, $a$, is a groove half

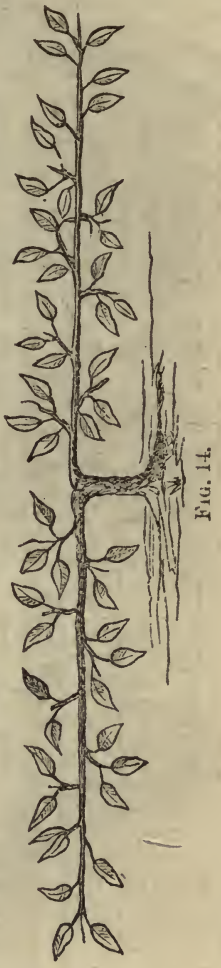
an inch deep; in the bottom bar, $b$, is a groove a quarter of an inch deep $;^{1}$ in the end bars, $c$ and $d$, are grooves half an inch deep. The pieces of glass, which should be cut so as to fit, are pushed into the upper groove, and let fall into the lower one when all are

1 An improvement on this is to have a rebate at bottom instead of a groove; the glass is more easily fltted in. 
fitted in ; the two end pieces are pushed inwards, so

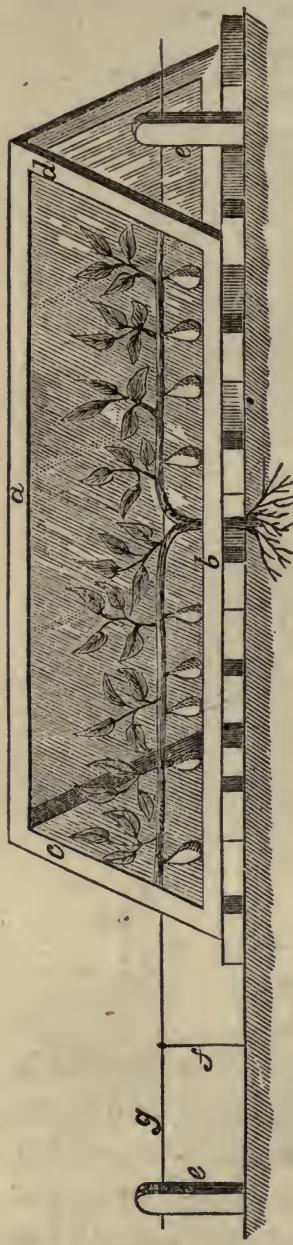

Fia. 15. as to drive all of them into close contact. A little putty is required at the bottom to prevent water lodging, and some at each end to keep the pieces from moving laterally, $e, e$, are the straining-posts of oak, four inches square; $f$, the upright pieces of wire stuck in the ground, flattened and perforated at top to pass the wire through and support it; $g$, the wire."

Such, then, is the description of the new barless fruit ridge-the invention of my son-which I think calculated to have a greater effect on domestic gardening, and contribute more to the refinement and comfort of a very large class of people, than all the crystal palaces ever invented. I feel that I ought to add how and where these nice things are to be bought.

Mr. James Rivett, builder, of Stratford, Essex, makes and sells them at 5s. 6d. or 6s. each, unglazed. Those who would wish to have a large number, and who live at a long distance from London, should have a few from Mr. Rivett as samples; they could then le imitated by any good laborer. 
For ventilation and other particulars, I refer my readers to the description of the ground vinery, pp. 121 to 127 ; and for the method of placing the wires, to p. 75 .

I must cantion those who wish to grow fruit under glass fruit ridges, in small confined gardens, to be careful as to ventilation. A single row of bricks, with interstices of four inches, will not be enough; there should be two rows of bricks, one over the other, and consequently two rows of interstices. Peach, nectarine, and apricot trees should be planted fourteen feet apart; but they grow rapidly, and would probably soon require removing.

It will thus be seen that to commence fruit ridge culture, four seven-feet lengths should be prepared, and in the centre of the twenty-eight feet occupied by the ridge two peach or nectarine trees may be planted. They will soon form lateral cordons of great fertility, and give constant employment in pinching to the amateur. I must not omit to state the great advantage this mode of fruit culture gives as to protection from spring frosts when the trees are in bloom, or when the fruit is young. Espaliers, pyramids, and wall trees are difficult to protect, but mats two or three thick can be piled on the ridge with great facility, and loose straw or hay, the best protectors possible from frost, can be strewed over them thickly.

\section{VERTICAL CORDON APPLE TREES.}

In pp. 42 and 43 will be found the method of training vertical cordon pear trees. This may be applied to apples on the English Paradise stock with great 
success, and very charming fiuitful trees they make. They should not be allowed to grow above seven feet in height, to which they will reach in the course of four or five years. I annex a figure of one of these trees, three years old, and full of fruit. (Fig. 16.)

PYRAMIDAL APPLES ON THE CRAB STOOK.

In soils light and poor, the apple on the Paradise stock is, unless carefully manured on the surface, apt

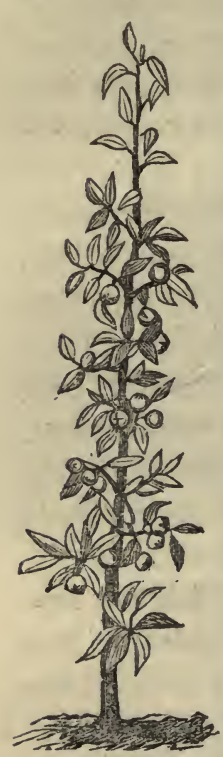

FIG. 16 to become stunted and unhealthy. In such soils, and also in those of a very tenacious nature, pyramids on the crab stock may be planted with great advantage. They are also well adapted for large gardens where large quantities of fruit are required, as the trees may be made to form handsome pyramids, from twelve to fifteen feet in height.

There is one thing most essential to their full success as pyramids-they must either be lifted or taken up biennially early in Norember, and replanted in the manner recommended for bush pear trees, or root-pruned biennially, operating upon the trees alternately, as mentioned in note to p. 12 ; or the following system may be adopted : neither remove nor root-prune any tree that continues to grow with moderation, does not canker, and bears well; but any tree that makes shoots from eighteen inches to three feet in length, remove once in two, three, or four years, till its vigorous habit is reduced. 
As these crab stock trees grow more fieely than the Paradise stock trees, summer pinching, or shortening the young shoots with a penknife, as recommended in p. 63, must be attended to, and then, in the most unfavorable apple tree soils, healthy and most prolific pyramids may be formed. Any of the varieties recommended in pp. 67 and 68 will succeed well as pyramids on the crab-stock.

If inanaged in this manner, fine trees may be formed, not only of the robust-growing kinds, but even of the old Nonpareil, Golden Pippin, Golden Reinette, Hawthornden, Ribston Pippin, and several others, all more or less inclined to canker. I have a row of Nonpareils and Ribston Pippins planted in the coldest and most unfavorable soil I could find, yet, owing to their being biennially removed, they are entirely free from canker.

The vigorous growth of standard apples, when planted in orchards in the usual way, is well known, and also their tendency to canker after a few years of luxuriant growth. Pyramids on the crab, without occasional removal, or root-pruning, would, in like manner, grow most freely, and, even if subjected to summer pinching, would soon become a mass of entangled, barren, cankered shoots.

\section{PYRAMIDAL PLUM TREES.}

The plum, if planted in a rich garden soil, rapidly forms a pyramid of large growth-it, in fact, can scarcely be managed by summer pinching. It becomes crowded with young shoots and leaves, and the shortening of its strong horizontal branches at the end 
of summer is apt to bring on the gum; it is a tree, huwever, with most manageable roots, for they are always near the surface. I must, therefore, again recommend summer pinching to three leaves, as directed for pears, p. 8, annual root-pruning, and surface dressing, in preference to any other mode of culture. The annual root-pruning of the plum is performed as follows :-Open a circular trench eighteen inches deep round the tree, eighteen inches from its stem, and cut off every root and fibre with a sharp knife. When the roots are so pruned, introduce a spade under one side of the tree, and heave it over so as not to leave a single tap-root; fill in your mould, give a top dressing of manure, and it is finished. The diameter of your circular trench must be slowly increased as years roll on ; for you inust, each year, prune to within one and a half or two inches of the stumps of the former year. Your circular mass of fibrous roots will thus slowly increase, your tree will make short and well-ripened shoots, and bear abundantly. From very recent experience, I have found that removing trees annually, if the soil be rich-biennially, and adding some rich compost, if it be poor-without root-pruning, will keep plum trees in a healthy and fertile state. For further particulars on this head, see pp. 13 and 14.

Pyramidal plum trees are most beautiful trees both when in flower and fruit. Their rich purple and golden crop has an admirable effect on a well-managed pyramid. No stock has yet been found to cramp the energies of the plum tree. I have, however, tried experiments on the sloe, which, as it never forms a tree of any bulk, effects this object to a certain extent. 
My trees on the sloe are some years old, and ara dwarf and prolific. The first year after grafting they made vigorous growth; but this is a very common occurrence with stocks that ultimately make very prolific trees; it is so with the pear on the quince, the apple on the Paradise, and the cherry on the Mahaleb. The greengage seems to grow more freely on the sloe than any other sort. I have three fine vigorous bushes, now about ten years old, growing in the white marly clay, with chalk-stones, peculiar to some parts of Essex and Hertfordshire. The sloe seems to delight in this soil, so inimical to most kinds of fruit trees. My greengage plums are almost vigorous in their growth; and what appears strange is, that the stock seems to keep pace with the graft-there is scarcely any swelling at the junction. The roots of these trees have not been touched, and they appear to have gone deeply into the solid white clay. The plum on the sloe is easily arrested in its growth by root-pruning. I have some trees, four years old, not more than eighteen inches high, and yet covered with blossom buds. ${ }^{1}$ These have been only once root-pruned, and are forming themselves into nice compact prolific bushes. As no peculiar culture, or disease, requires to be noticed, I have only to give a selection of sorts calculated for pyramids. These are also well adapted for walls with W., N. W., E., or S. E. aspects.

1 Since this was written, I have found plums grafted on the plum stock so easily dwarfed by annual or biennial removal, that, unless in lard clayey soils, fisund to be unfavorable to the plum, there is no occasion to employ the sloe stock, unless as an experiment. 
HARDY DESSERT PLUMS ADAPTED FOR PYRAMIDS.

In season from July to the end of Octoler. Placed in the order of their ripening.

Early Favorite*
July Green Gage*
De Montfort
Oullins's Golden Gage.
Green Gage*
Jefferson*

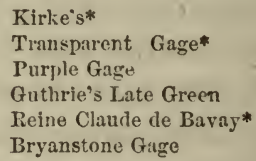

HARDY KITCHEN PLUMS ADAPTED FOR PYRAMIDS.

In season from July till the end of October. Placed in the order of their. ripening.

Early Prolific*

Belgian Purple*

Pond's Seedling

Prince Englebert

Victoria or Alderton*

Mitchelson's

Dove Bank

Diamond*

Imperial de Milan

Autumn Compote*

Late Black Orleuns*

Belle de Septembre*

PLUM TREES AS BUSHE.

There is, perhaps, no fruit tree so easily kept within bounds as the plum. In rich soils they bear annual removal with but a slight check; but in most soils biennial removal will keep them in a perfectly fruitful state in bush culture. This is absolutely necessary; and if the soil be poor, some thoroughly rotted manure (about half a bushel to each tree) may be mixed with the soil in replanting. As with pear trees, the best season for lifting or removing them is the end of October or beginning of November. Plum bushes have the advantage of being easily protected by a square of light cheap calico, tiffany, or any light material, thrown over them while in blossom, and a crop of fruit thus insured. All the varieties recommended for pyramids may be cultivated as bushes, and, for suburban gardens, they should be subjected to exactly the same treatment as recommended for apple bushes, p. 67 . 
CHERRIES AS BUSHES AND PYRAMIDS ON THE MAHALEB STOCK (CERASUS MAHALEB).

This stock has been long known in our shrubberies as the "Perfumed Cherry:" its wood when burned emits a most agreeable perfume. In France it is called "Bois de St. Lucie," and it has been used there for dwarf cherries for very many years; -why it has not been employed by English nurserymen, I cannot tell. My attention was called to it in France some fifteen or twenty years ago, since which I have used it extensively, annually increasing' my culture. Its great recommendation is, that cherries grafted on it will flourish in soils unfavorable to them on the common cherry stock, such as strong white clay, or soils with a chalky subsoil. Although the trees grow most vigorously the first two or three seasons, yet, after that period, and especially if root-pruned, they form dwarf prolific bushes, so as easily to be covered with a net, or, what is better, with muslin or tiffany, which will protect the blossoms from frost in spring, and the fruit more effectually from birds and wasps in summer; thus giving us, what is certainly most rare, cherries fully ripe, and prolonging their season till the end of September. These dwarf bushes may be planted from five to six feetapart, and their branches pruned so that seven, or nine, or more, come out from the centre of the plant, like a well-managed gooseberry bush. These branches will, in May or June, put forth, as in the horizontal shoots of pyramidal, pears, several shoots at their extremities, all of which must be pinched off to three leaves, leaving the lead- 
ing shoots untouched till the middle or end of August, when they must be shortened, and the pruning for the year is finished.

The Morello and Duke cherries-the most eligible for this bush culture-may have their leading shoots shortened to eight leaves. If, however, the space be confined in which they are planted, this length may be reduced, for by biennial root-pruning the trees may be kept exceedingly dwarf. The end is to form the tree into a round bush, not too much crowded with shoots. Towards the end of September, ${ }^{1}$ or, in fact, as soon as the autumnal rains have sufficiently penetrated the soil, a trench may be dug round the tree, exactly the same as recommended for root-pruning of pears, the spade introduced under the tree to cut all jerpendicular roots, and all the spreading roots shortened with the knife, and brought near to the surface, previously filling in the trench with some light friable soil for them to rest on, and spreading them regularly

- round the tree, as near to the surface as possible; then covering them with the soil that was taken out of the trench. No dung or manure of any kind is required, as this stock seems to flourish in the poorest soils. Some short litter, or half-decayed leaves will, however, be of much benefit placed on the surface round the stem.

I have thus far given their culture for small gardens; but those who have more space may dispense with root-pruning, and allow their cherry trees to make large bushes, which may be planted eight feet

1 This early antumnal root-pruning will be found very advantageous. The flow of sap is checked, so that the shoots are well ripened, and the pruned routs soon cmit fresh fibres to feel tho tree the following season. 
apart, and pinched regularly in the summer, and managed as directed for pear trees (p. 8). The leading shoot from each branch in such cases must be left longer, and shortened to twelve or more buds.

The most charming of all pyramids are the varieties of the Duke and Morello cherries on the Mahaleb ; these by summer pinching, as practised for pyramidal pears, become in two or three years the most delightful fruit trees ever seen, for in spring they are perfect nosegays of flowers, and in summer clusters of fruit-if spared by spring frosts.

The common Morello cherry on the Mahaleb stock, cultivated as a pyramid, forms one of the most prolific of trees; but as birds carry off the fruit when only half ripe, each pyramid should have a bag of tiffany placed over it, and tied round the stem of the tree at bottom. Any garden, however small, may grow enough of this useful sort by planting a few pyramids, lifting and replanting, or root-pruning them biennially, and pinching in every shoot to three leaves (as soon as it has made five) all the summer. The Kentish cherry, also a most useful culinary sort, may be cultivated as a pyramid with great success. A French variety grown near Paris, in large quantities, and known as the "Cerise Aigre Hầtive," which may be Englished by calling it the Early Sour Cherry, is a useful kind for the kitchen. In going from Paris a year or two ago to Versailles by the "Rive Droite" Railway, I was much struck by seeing in the market gardens between Suresnes and Puteaux, on the left, large plots of dwarf trees, about the size of large gooseberry bushes, and some very low trees, all cov- 
ered (as they appeared to me from the railway carriage) with bright red flowers. I learned, on inquiry, that these were cherry bushes-literally masses of fruit, of the above variety. I find, however, that it is not equal to the Kentish in flavor or size in England.

I need scarcely add, that the culture of all the Duke tribe of cherries by closely pinched-in pyramids, biennially removed, or biennially root-pruned, is most satisfactory. It is, perhaps, more easily performed than root-pruning, and the trees soon form perfect pictures. As far as my experience has gone, cherries on the Mahaleb are much more fruitful when "oft removed ;" the most eligible mode is to remove only half the trees in one season, and the remainder the following season. I have seen nothing in fruit-tree culture more interesting than handsome compact pyramids of such sorts of cherries as the May Duke, Duchesse de Palluau, Empress Eugénie, and Archduke. One feels surprise to find that as yet but few lovers of gardening know of the existence of such trees.

It will much facilitate the operation on their roots, if the trees be planted on small mounds.

In forming plantations of pyramidal and dwarf cherries on the Mahaleb stock, it is necessary to arrange them with a little care. The two groups, those of the habit of the Morello tribe, and those of the compact habit of the May Duke, should be plantcd in separate rows. Bigarreau and Heart cherries are too short-lived, when grafted on this stock, in most descriptions of soils, to be recommended. 
The following arrangement will assist the planter :-

SEction I.-The May Duke Tribe.

\begin{tabular}{l|l} 
Arch Duke* & Belle de Choisy \\
May Duke* & Nouvelle Royale \\
Royal Duke* & Empress Eugénie \\
Jeffrey's Duke & Duchesse de Palluau
\end{tabular}

SECTION II.-The Morello Tribe.

Carnation (Coe's Late)*

Kentish

Late Duke*

Griotte de Chaux*
Morello*

Reine Hortense*

Belle Magnifique

Planchoury

Cherries planted on the Cerasus Mahaleb are eminently adapted for espaliers, or for walls, as they occupy less space, and are much more fertile. They may be planted twelve feet apart, whereas espaliers on the cherry stock require to be planted eighteen or twenty feet apart. For potting, for forcing, cherries on this stock are highly eligible, as they are very prolific. $^{1}$

\section{CHERRIES ON VERTICAL CORDONS.}

The varieties best adapted for this very interesting mode of culture are those of the Duke tribe, such as the May Duke, Arch Duke, Empress Eugénie, Royal Duke, Nouvelle Royale, Duchesse de Palluau, and some others. They require the same summer pinching as that recommended for vertical cordon pears, $p$. 42. Nothing can be more charming than these cordon cherry trees. I have at this moment trees only two years old, of the Duke tribe, with their bright ripe fruit hanging close to the stem, and shining through the net that protects them from the birds.

1 Cherry trees are often infested in summer with the black aphis. The best remedy is a mixture made by boiling four ounces of quassia chips in a gallon of soft water ten minutes, and dissolving in it as it cools four ounces of soft soap. It should be stirred, and the trees syringed with it twice or thrice. The day following, they should be syringed with pure water. 
A PYRAMIDAL MORELTO CHERRY TREE. From a Photograph, August, 1862.

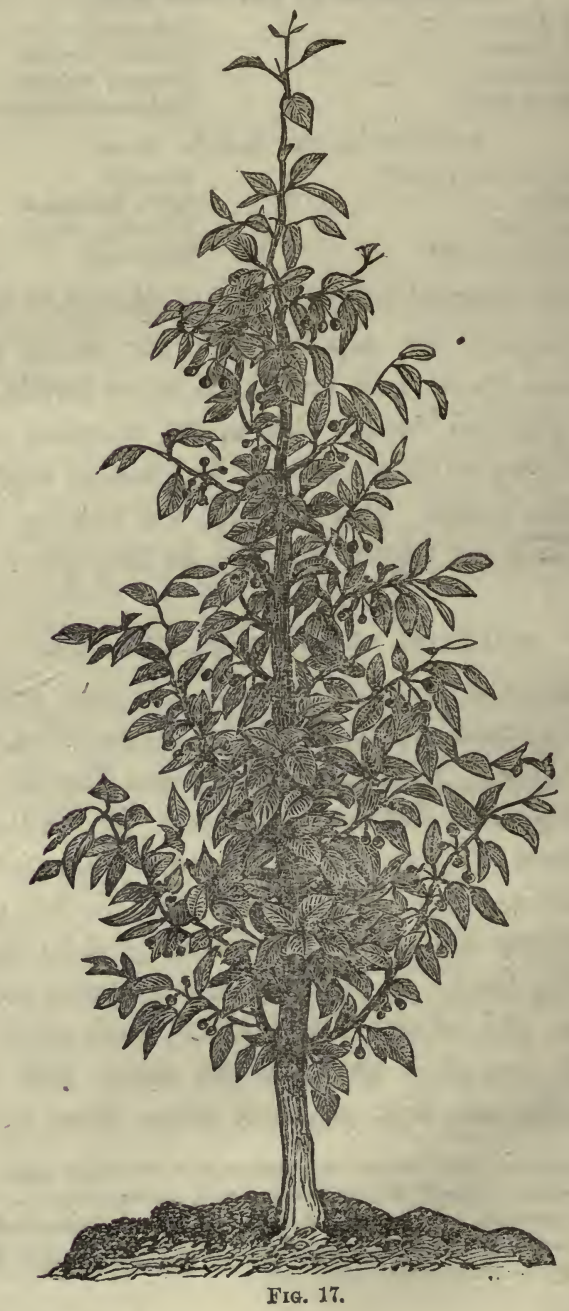


The best of all protection, both from birds and wasps, is, however, Haythorn's netting, or coarse muslin, formed into a narrow bag, which should be let down gently over the tree, and tied at the bottom; Duke cherries may thus be preserved till Augnst. I may mention here, that with all these cordon trees, rootpruning or removal is seldom required, their vital force is so reduced by continuous pinching of the young shoots; but if a rich soil gives too much vigor, it may be practised. There are a few kinds of plums, of upright growth, which may also be cultivated as vertical cordons.

The Bigarreau and Heart, or Guigne cherries, are too vigorous for this mode of culture when grafted or budded, as they generally are, on the common cherry stock. The new mode of culture by double grafting, i. e., by grafting them on young trees of the common Morello cherry that have been grafted on the Mahaleb, will make them must prolific cordons. (See p. 102.)

I must add a piece of very necessary advice: all cordon trees, whether pears, apples, cherries, or plums, should be supported by a slight iron rod, about the size of a goose-quill, which should be painted; this should stand six to seven feet above the surface, and be inserted ten to twelve inches in the ground, and the tree attached loosely to it by two or three ligatures of copper wire.

BIGARREAU AND HEART CHERRIES AS PYRAMIDS ON THE COMMON CHERRY STOCK.

Among the mysteries of vegetable physiology, there is nothing, perhaps, more interesting than the facts 
discovered by the fruit-cultivator. Many kinds of pears grow with great luxuriance when grafted or budded on the quince stock, while other kinds, cultivated in the same soil, and budded or grafted with equal care, will grow feebly, and die in the course of a year or two.

The Noblesse and Royal George peaches form fine healthy trees when budded on the Muscle plum stock. The Grosse Mignonne and the French Galande die in a year or two, if budded on it. The Moor Park apricot grows readily and freely on the above-named stock. The peach apricot, its French congener, will not; why? The Bigarreau and the Heart cherries (or, as the French call them, Guignes) do not succeed well on the Cerasus Mahaleb; they grow most rapidly for two or three years, and then generally becorne gummy and diseased.

The stock raised from the small black and red wild cherries is the proper one for this race, except they are double grafted.

Pyramidal cherry trees may be bought ready-made, or formed by purchasing young trees, one year old, from the bud, and training them up in the same way as directed for pyramidal pears (pp. 4 and 5), with this variation-pears, as is well known, may be grown as pyramids successfully, with or without root-pruning or biennial removal; but cherries on common cherry stocks will grow so rapidly, in spite of summer pinching, that biennial removal is a work of necessity. In the course of a few years, pyramidal cherry trees thus treated become pictures of beauty. In France they generally fail, and become full of dead stumps 
and gum, owing to their trusting entirely to pruning their trees severely in summer and winter, without attending to their roots; the trees thus being full of vigor make strong shoots, only to be pinched and cut off. We must "manage these things better" in England.

The mode of operation in removing pyramidal cherries is the same as that recommended for pears and apples, \&c. It will be found, however, that more labor is required, for in two years the cherry on the common stock, like the apple on the crab, makes a vigorous attempt to lay hold of its parent earth. The second year the tree may be lifted by digging a trench round its stem, one foot from it and 16 inches deep. The fourth year this trench must be made 18 inches from the stem and 20 inches deep; the sixth year it should be 2 feet from the stem and 2 feet deep. This distance and depth need not be departed from if the trees are required to be only fair-sized pyramids; the straggling roots beyond this circumference should be biennially pruned off with the knife. The tree managed thus will soon be in a mature, fruitful state, and its roots a mass of fibres, so that when removed it will, like the rhododendron, receive only a healthy check.

Pyramidal Bigarreau and Heart cherries, cultivated after the method above given, may be planted in small grass orchards, with pyramidal pears on pear stocks, pyramidal apples on crab stocks, and pyramidal plums. A charming orchard in miniature may thus be formed. Cattle and sheep must, of course, be excluded. 
The following varieties form handsome pyramidal trees, and bear fruit of the finest quality :-

Belle d'Orleans*
Bigarreau
Bigarreau Napoléon
Black Eagle*
Black Tartarian
Downton

Elton*

Flurence*

Governor Wood*

Knight's Early Black*

Ohio Beauty

Werder's Early Black

I have thus far given the results of my experience in the culture of pyramidal trees. The method is not by any means new, for visitors to the Continent, for these last fifty years, must have often observed the numerous pyramids of France and Belgium. The system of annual and biennial root-pruning I must, however, claim as original, for I feel assured that in our moist climate-too moist for many varieties of fruit-such check is required to keep pyramids that are under summer pinching in a healthy, fruitful state. The defect in the pyramidal trees of the Continental gardeners is their tendency to an enormous production of leaves and shoots, brought on by serere annual pruning of their shoots. The climate is probably too dry for root-pruning; yet I cannot help thinking that if it were followed by manuring thickly on the surface, and occasional watering, it would make their trees prodigiously fruitful.

At the risk of repetition, and writing from my own experience, I must say that no gardening operation can be more agreeable than paying daily attention to a plantation of pyramids. From the end of May to the end of July - those beautiful months of our short summer-there are always shoots to watch, to pinch, to direct, fruit to thin, and a host of pleasant operations, so winning to one who loves his garden and every tree and plant in it. 
To conclude, I may mention that the small Alberge apricot, raised from the stone, and producing small high-flavored fruit, and also the Breda apricot, make very beautiful pyramids if lifted or planted biennially. In the southern counties of England, in a favorable season, they will ripen their fruit, and produce good crops. The large Portugal quince is also very prolific as a pyramidal tree. Some trees only two years old have borne fine fruit here. This is the finest of all the quinces, and in the south of Europe it grows to an enormous size. The Medlar will also form a handsome and productive pyramid, and, "last, but not least" in the estimation of the lover of soft fruits, the currant. A near neighbor-an ingenious gardener -attaches much value, and with reason, to his pyramidal currant trees; for his table is supplied abundantly with their fruit till late in autumn. The leading shoots of his trees are fastened to iron rods; they form nice pyramids of about five feet in height; and by the clever contrivance of slipping a bag made of coarse muslin over every tree as soon as the fruit is ripe, fastening it securely to the-bottom, wasps, and birds, and flies, and all the ills that beset ripe currants are excluded. With all these, summer pinching and root-pruning, or biennial removal (except the currant, which does not require the latter operation), as directed for pears, are indispensable; they soon form very handsome pyramids, and make a pleasing variety in the fruit garden.

FILBERTS AND NUTS AS STANDARDS.

Filberts, as commonly cultivated, except in the $5^{*}$ 
Kentish gardens, form stragigling bushes, and are some years before they commence to bear. To correct this, I some ten or more years since had them grafted on stems of the hazel-nut raised from Spanish nuts, as they were vigorous growers and formed stout stems. I have found these grafted trees answer admirably, and come quickly into bearing, forming nice garden trees.

As soon as the nut trees designed for stocks have made stout stems about four feet high, they should be grafted at that height with the choice kind of nuts, such as red and white filberts and the Cusford nutan excellent nut. The purple-leaved filbert, generally planted as an ornamental shrub, may also be grafted; it gives nuts equal to the common filbert, and forms a nice ornamental standard.

Standard nuts require but little culture; they soon form round heads, and bear profusely. Care must be taken to destroy all suckers from the stem and root.

The only pruning required is in winter, to thin out the crowded shoots, and shorten to half their length those that are inclined to be vigorous - that is, those that are more than nine inches in length. The short spray-like shoots must not be shortened, as they are the fruit-givers.

If these standard nuts are planted in rich garden soils, they will soon make trees too large for small gardens. If, therefore, they are found to grow ton vigorously, they should be lifted and replanted biennially in November.

I have mentioned seedling nuts as good for stocks; but I have lately employed a valuable sort introduced 
from Germany as Corylus arborescens; this makes a beautiful clear stem.

The Algiers nut, Corylus algerensis, seems also to be well adapted for a stock for standards, as it makes shoots from six to seven feet in one season.

\section{FIGS AS HALF STANDARDS OR BUSHES.}

There is, perhaps, no fruit tree that disappoints the amateur fruit grower so much as the fig. If planted in the open borders of the garden, it soon grows into an enormous fruitless bush or tree, and if placed against a wall, unless a very large space can be given to it, but little fruit must be expected.

It may, however, be made eligible for small gardens, where the climate is sufficiently warm to ripen its fruit, such as the gardens near London, and those in the eastern and southern counties. Fruitfulness and moderate growth are brought on by the following method. Trees should be procured of the Brown Turkey or Lee's Perpetual, White Marseilles and Early Violet Figs-these are the only kinds that bear freely, and ripen their fruit well-such trees should be low or half standards, or dwarfs with a clear stem (not bushes branching from the ground). The former should have a stem three feet high, and the latter one from one foot to eighteen inches; in each case the tree should have a nice rounded head.

Trees thus selected should be planted in a sunny situation, and require only the following simple mode of treatment. They, we will assume, were planted in March or A pril. They will make a tolerably vigorous growth, and must be pruned by pinching off the top 
of every shoot as soon as it has made six leaves, leaving five. The stem must be kept quite clear from young shoots. By the autumn, nice round-headed trees will be formed, and about the end of October they should be taken up (their leaves cut off, if they have not fallen) and placed in a cellar-no matter if dark, but a light dry cellar would be preferable-some earth should be placed over their roots, and there they may remain till the first week in May, when they should be planted out, and the same routine of culture followed. They will bear one good crop of fruit in a season, and ripen it in September. This annual removal brings on great sturdiness of growth in the tree, and the roots becomes so fibrous as to hold a large quantity of earth, which should not be shaken from them when they go into their annual winter abode. In the year $1857 \mathrm{I}$ saw fine trees thus treated in the garden of the Duke of Altenburg, in Central Germany; their stems were as stout as a man's leg and their heads full of fruit; and this season, 1865, my fig-tirees, taken up last October, and placed in the orchard-house during the winter-their roots in the soil-have given me a crop of very rich, well-ripened fruit. The roots that have borne best are the Brown Ischia, Brown Turkey, and Brunswick.

THE BIENNIAL REMOVAL OF FRUTT TREES WITHOUT ROOT-PRUNING.

For some few years past I have felt a growing conviction that peach trees trained against walls in the usual manner, without careful root-cultivation, cannot, in our climate, be kept in a state at all healthy 
or fertile for a series of years. A wall covered with healthy peach or nectarine trees of a good ripe age is rarely to be seen; failing crops and blighted trees are the rule, healthy and fertile trees the exception. The following mode of treating peaches, nectarines, apricots, and plums on the removal system I have found simple and efficacious.

Supposing a trained tree, of the usual size, to have been planted in a border well prepared-i.e., stirred to a depth of twenty inches; it may be trained to the wall as usual, and suffered to grow two seasons. Toward the end of October, or, indeed, any time in November in the second season, it should be carefully taken up, with all its roots intact. If there be two or three stragglers-i.e., roots of two or three feet in length-for roots are remarkably eccentric, and often, without any apparent cause, run away in search of something they take a fancy to-cut off' one foot or so, so as to make the roots of the tree more snug. Then make the hole from whence you took your tree a little deeper, and fit to receive its roots without bending or twisting. Place in it any light compost. If the soil be heavy, leaf-mould, rotten manure, and loam, equal parts: if it be light, two-thirds tender loam, not sandy, and one-third rotten manure. Two inches deep of this compost will be enough for the roots of the tree to rest on ; and mind they are carefully arranged, so as to diverge regularly: then add enough of the compost to cover all the roots, and fill in with the common soil, so as not to cover the surface roots more than two inches deep. If the soil be light, the surface should be trodden down very firmly, 
and then have a dressing of old tan, or decayed litter.

A tree that has been planted two years will require one barrowful of the above compost; at the end of four years, two barrowfuls; when six years have passed, from three to four barrowfuls; and from four to six barrowfuls will be enough for a tree from twelve to twenty years old-in short, for a full-grown tree. A portion of the earth from the border must be removed when a large quantity of compost is added, to make room for it, so as not to have an unsightly mound. In the course of two or three removals, the roots of the tree will become a mass of fibres, and the trees so docile as to be lifted without difficulty.

I have this day (Dec. 12, 1852) removed two plum trees that have been planted six years and removed twice. Their roots are a mass of fibres without one straggling root; they have been replanted with a barrowful of light compost to each tree, ${ }^{1}$ and, if I may judge by the enormous quantity of blossom buds, they will bear a plentiful crop next season. They will receive no unhealthy check, for abundance of earth adheres to the mass of fibrous roots. Now, as peaches, nectarines, and apricots, being budded on plum stocks, are all on plum roots, they will give exactly the same results from the same mode of culture, neither the size nor flavor of the fruit will be affected, and the trees will always bear abundantly, and be healthy and flourishing.

1 The soil is rich, and one barrowful I thought quite enough. The quantity of compost must be regulated by the wants of the soil, for in rich solls, where peaches and nectarines are apt to grow too freely, no compost need be added, but the tree merely liftel and replaced. A peach, nectarine, or apricot tree, uniler the removal system, that makes annual shoots more than fifteen inches in length, is two luxuriant, and will require no compost to its roots when replanted. 
The plethoric habit of the Moor Park and Peach apricots, which so often leads to disease and death, will be effectually cured by this simple mode of culture, and peaches and nectarines will make short annual shoots, which will be always well ripened, so that they will be constantly full of healthy blossombuds. For trees under Mr. Ker's trellises, it answers admirably. Some mulch, or old tan, two inches in depth, placed on the surface of the soil so far as the roots spread during the spring and summer, will be of much service.

All trees that are inclinëd to make very fibrous roots, such as plums, pears on quince stocks, and apples on Paradise stocks, may be lifted-i. e., removed biennially, as above described-with equal or greater facility than root-pruning them. The effect is the same : they make short, well-ripened shoots, and bear abundantly. Apples on Paradise stocks, cultivated as dwarf bushes or as pyramids, if lifted every year, and a shovelful or two of compost given to them, form delightful little trees. ${ }^{1}$ The most delicate sorts of apples, such as Golden Pippins and Nonpareils, may thus be cultivated in the most unfarorable soils; and Roses, more particularly Bourbon Roses on short stems, and Hybrid Perpetuals, removed annually in the autumn, giving to each tree a shovelful of rich compost, and not pruning their shoots till April, will bloom delightfully all the autumn, never dropping their leaves towards the end of summer, and becoming, as is too often the case, blighted and blossomless.

I In moist retentive soils, the fruit-spurs of small trees become covered with moss; some powdered lime sprinkled over them will destroy it; this is best done in finggy weather in winter. 
To conclude, I will, as a guide to the amateur, give the following summary :-If the soil be very rich, so as to induce the trees planted in it to make a growth of eighteen inches in one season, they may be removed annually till this vigorous growth ceases. If the trees make an annual growth only of eight to ten inches, the trees may be removed biennially, and I may add that, in soils in which trees grow slowly, root-pruning is more advantageous than removal, as less check is given to vegetation.

\section{DOUBLE GRAFTING OF FRUIT TREES.}

I have not been able to find this mode of culture, likely to be so beneficial to fruit gardens in England, alluded to by the many authors of works on fruit trees; it may be "as old as the hills," and have no claim to originality, but few so-called new ideas have. I can only therefore state how it originated here some fifteen or twenty years since. I am not aware that it has been practised by the clever fruit tree cultivators of France and Belgium; if so, it has been recently copied from English practice, but I never remember having seen it carried out.

Its history, briefly told, is as follows:-I observed, when budding and grafting pears on the quince stock, that some varieties did not grow freely on that stock, when budded or grafted; particularly the Gansel's Bergamot and the Autumn Bergamot, the Seckel, the Marie Louise, Knight's Monarch, and some others. Now, as the first and last mentioned are notorious for thoir shy bearing qualities, while the trees are young, 
even when root-pruned or frequently removed, I felt anxious to see them flourishing on the quince stock, - which invariably makes pear trees fertile. I found that but few grafts of these sorts out of scores would survive on the quince, and when they did unite they were very short lived; this induced me to look narrowly into the habits of pear trees on the quince stock, and I found that the Beurré d'Amanlis formed a most perfect union with the stock, and seemed most enduring, for I had seen trees in France at least fifty years old. I therefore fixed upon this sort for my experiment, and had thrifty trees, two years old from the bud, grafted with Gansel's Bergamot; the grafts flourished, and became so prolific that, when three or four years old, they each bore from three to four dozen of fruit-a most unusual thing with that fine variety. This scttled the question as to the fertility given by double grafting, which, since this experiment, has become here an extensive branch of culture. There are other kinds of pears which, from uniting with and growing freely on the quince stock, serve well for double grafting, such as Prince Albert, Bezi Goubault, and Conseiller de la Cour. Prince Albert is a sort well adapted for the Monarch, Marie Louise, Prince of Wales (Huyshe), Victoria (Huyshe), and British Queen; Beurré d'Amanlis may be used for the Jargonelle and Bergamots, as may also Bezi Goubault, the hardiest pear known. The cultivator has something to learn, for there are many pears of the finest quality, but of a delicate and infertile habit, that may be much improved by double grafting.

Our garden culture of cherries is, as yet, rude and 
imperfect; and espaliers of the Bigarreau and Guigne or Heart tribe are planted and trained along the sides of the garden walks, giving abundance of shoots and leaves, but very little fruit (which the birds appropriate), and in the course of time give out gumowing to their having been unmercifully prunedand die full of years and barren shoots, having given much trouble to the gardener. I have pointed out how cherries may be cultivated in gardens as pyramids, \&c., and have alluded to fertility in the Bigarreau and Heart tribe being promoted by double grafting; this mode of culture is also interesting, as leading to success in soils that seem unfavorable to cherries under some circumstances.

Cherries grafted on the Mahaleb are described pp. 85 to 90 ; they affect calcareous soils, and, as far as I can learn, do not succeed so well in the sandstone formations, and where iron abounds in the soil; in such situations, double grafted trees should be planted formed in this way-the common Morello cherry should be budded on the Mahaleb stock, and after two years it should be grafted with some kind of Bigarreau, Heart, or Guigne cherry; it will form a small or moderate sized tree, and bear abundantly. In cultivating cherry trees in soils inimical to their welldoing, abundance of chalk or lime rubbish should be mixed with the earth to the depth of two feet.

Double grafting of apples is of very inferior importance as compared with the same operation on pears or cherries, for our English Paradise stocks give the most perfect health and fertility in nearly all soils. Still there may be some peculiar positions, where the 
soils are very light and poor, in which strong, robust sorts of the crab stock are required to make healthy fruitful trees. In such cases it is better to graft such sorts as the Hawthornden, Manx Codlin, and Small's Admirable, on thrifty crab stocks, and when two years old regraft them with choice dessert kinds : all double grafting is best done when the first graft is two years old. I have now pointed out to a certain extent the advantages of double grafting, but much must be left to the intelligent amateur. It is to be regretted that English cultivators, more particularly nurserymen, have not turned their attention to the benefit choice fruit trees derive from having the proper kind of stock selected for them, or from being double grafted. Mr. George Lindley, father of Dr. Lindley, seems to have turned his attention to fruit tree stocks, more than any other nurseryman of his day; still he knew only those grown by the Surrey Nurserymen of the present day-a very imperfect list-for nurserymen, like farmers, move slowly. It is but a few years since that the common fruit-bearing quince, raised from layers - a most unfit stock-was sold in Surrey for stocks for pears, and Muscle, White Pear plum, Brompton, Brussels, and "Commoners" (i.e., common plum stocks), are still the plum stocks propagated in Surrey for sale; all except the first and the last are of inferior quality and are surpassed by the French stock, the Black Damask plum, which suits Peaches, Nectarines, Apricots, and all kinds of plums.

The double budding of some kinds of peaches and nectarines is almost necessary to their well doing in some soils, yet this method of culture seems to have 
been neglected by European nurserymen. The truth must be confessed, that nurserymen, as a class, have but little taste for pomology ; they take to flowers and plants eagerly, becaúse they give a quick return; and thus Pornona and her gifts are always placed in the shade-as to experiments, "they do not pay." There are some free growing kinds of apricots which, when budded on the plum, and the young apricot budded with a peach or nectarine, produce the most favorable effects on the peach tree, the union being perfect and the duration of it much lengthened. There are also one or two kinds of plums which, being budded on a wild kind of plum, furnish when double budded a most favorable stock for the peach, giving it hardiness and fertility. We are still very backward in our knowledge of the effects of stocks on fruits; the subject requires much time and research, and no rushing to conclusions like some of our writers, who write on every thing and nothing well, only because they have not the necessary patience to master a few subjects thoroughly.

HOW TO PREPARE A PEACH TREE BORDER IN LIGHT

\section{soILs.}

In our southern counties, where light sandy soils abound, the difficulty of making peach and nectarine trees trained to walls flourish is well known ; in spring they are liable to the curl and the attacks of aphides, in summer they are infested with the red spider, so that the trees are weakened, and rarely give good fruit: they seem, indeed, to detest light soils. The following method of preparing borders for them in such 
soils may be well known, but I have not seen it described by any gardening author. The idea has come to me from observing peach trees, trained to walls, refuse to do well in the light sandy soil forming a part of my nursery, except near paths, and to grow and do well for years in the stiff tenacious loam forming another part. My bearing trees in pots, for which I use tenacious loam and dung, rammed down with a wooden pestle, also bear and flourish almost beyond belief; and so I am induced to recommend that, in light soils, the peach tree border should be made as follows:-To a wall of moderate height, say nine or ten feet, a border six feet wide, and to a wall twelve feet high, one eight feet wide should be marked out; if the soil be poor and exhausted by cropping, or if it be an old garden, a dressing of rotten dung ${ }^{1}$ and tenacious loam, or clay, equal parts, five inches in thickness, should be spread over the surface of the border: it should then be stirred to two feet in depth, and the loam and dung well mixed with the soil. The trees may be planted during the winter, and in March, in dry weather, the border all over its surface should be thoroughly rammed down with a wooden rammer, so as to make it like a well-trodden path; some light half-rotten manure, say from one to two inches in depth, may then be spread over it, and the operation is complete. This border must never be stirred, except with the hoe, to destroy weeds, and, of course, never cropped: every succeeding spring, in dry weather, the ramming and dressing must be repeated, as the soil is always much loosened by frost. If this

1 If the border be new or rich with manure, a dressing of the loam, or clay only, four inches in thickness, will be sufficient. 
method be followed, peaches and nectarines may be made to flourish in our dry southern counties, where they have hitherto brought nothing but disappointment.

The two grand essentials for peach culture are stiff loam and a sunny climate.

\section{A CHEAP METHOD OF PROTECTING WALL TREES.}

At Twyford Lodge, near East Grinstead, Sussex, the seat of R. Trotter, Esq., is a wall 75 feet long, covered with peaches and nectarines, which, for several years, had given no fruit; some years ago, the gardener, Mr. Murrell, asked my advice about protecting it with glass; and, acting upon it with his own adaptation, has succeeded, every season since its erection, in securing fine crops of fruit of superior flavor. The following is a description of this simple structure :-

At the top of the wall, which is 12 feet high, is nailed a plate for the ends of the rafters to rest on ; 4 feet 6 inches from the wall is a row of posts, 6 inches by 4 (these should be of oak), 6 feet apart, and 3 feet 6 inches in height, from the ground ; on these is nailed a plate to receive the lower ends of the rafters; the latter are 8 feet long, 3 inches by $1 \frac{1}{2}$, and 20 inches asunder; and the glass employed is $16 \mathrm{oz}$. sheet, 20 inches by 12. Every fourth square of glass at the top next the wall is fixed into a slight frame of wood, with a hinge at the top of each, and made to open all at once by a line running in a wheel; the front is of $\frac{3}{4}$-inch deal boards nailed to the posts, one of which, one foot wide, near the top, is on hinges, forming a 
drop shutter the whole length of the front. Now comes the management by which red spider, the deadly foe of the peach tree, is discomfited; and let me quote Mr. Murrel :-

"All these ventilators, back and front, I leave open day and night after May, except in very wet and rough weather. The first season I had the red spider (it was in the walls), but the fruit was of the highest flavor ; the second season the fruit was very fine, and the spiders never came, I believe, owing entirely to my syringing the trees twice a day, morning and afternoon, and leaving all the ventilators open; besides this, the boards have shrunk, so that there are wide crevices, and the place is always airy. I thank you for your hints about giving plenty of air ; the trees are admired by all who see them."

The roof, it will be seen, is fixed, and the whole structure a fixture; the trees can be pruned and nailed under shelter, and a crop of fruit always insured; how superior, then, is this to all the temporary protectors for walls so often recommended!

\section{STANDARD ORCHARD TREES.}

Although in this little work I profess to confine myself to the culture of garden fruit trees, I feel that a few words as to my method of planting trees in an orchard under grass may not be out of place, for very frequently a villa residence may have a piece of pasture land attached to it favorable to the growth of orchard trees, and quite necessary as a convenient place for the cow or the horse or horses. The common practice is to open large holes in the turf, six 
feet in diameter, and from two to three feet. deep; and in the centre to plant a tree. In rich deep loamy soils trees often succeed when planted in this manner, and as often fail, the hole becoming in wet seasons a pond.

Orchard trees, as a general rule, should be planted twenty-four feet apart, row from row, and they are for the most part planted twenty-four feet apart in the rows, so as to sitand that distance apart over the whole orchard. I now propose that the rows should be twenty-four feet apart, but the trees twelve feet apart in the rows, so as to allow of one-third more trees to the acre. Instead of digging large holes, slips, six feet wide, should be marked out on the turf, so that the centre of each is twenty-four feet apart; each slip should then be trenched, or, as it is often called, " double-dug," to a depth of two feet, turning the turf to the bottom of the trench and bringing the subsoil to the surface. A row of trees should be planted in the centre of each slip, twelve feet apart, and after the lapse of some fifteen or twenty years every alternate tree should be either removed and replanted or grubbed up. As such large standard trees would require much care in transplanting, and even then probably not succeed, the latter may prore the more economic mode. By thus planting more trees than required for a permanent orchard, a great advantage is reaped, for the temporary trees will, if the land is good, bear a large quantity of fruit, and amply repay their cost, which is trifling; for whereas ninety-five trees are required to plant one acre, twenty-four 'feet apart, by the above method 142 may be planted. I 
have mentioned from fifteen to twenty years as the probable time when the temporary trees may be removed; as this depends entirely upon the quality of the soil and the progress they have made, a more certain rule to lay down is, that, as soon as the outside shoots of the trees touch each other, the temporary trees should be removed. I need scarcely write the usual directions as to the trees being fenced round, if horses and cows are turned into the orchard-that the trees should have stems at least six feet in height, and the lower branches should be taken off as soon as they become depressed enough for cattle to browse on them. One direction I feel, however, bound to give-a circle from three to four feet in diameter round each tree should be kept clear of grass and weeds for at least five years from the time of planting; after that period, grass may be allowed to cover all the surface, as in old orchards.

In preparing the slips by trenching, if the subsoil be poor and stony, it should not be brought to the surface, but be merely turned over with the spade, and some manure mixed with it, keeping the turfwell chopped-and the loose mould on the surface. If the soil be wet, drains four feet deep should be made twenty-four feet apart, one in the centre of the space between each row of trees; they should be made with loose stones, which are far better than pipes for orchards. The bottom of the drain should be filled to the depth of eighteen inches with loose stones, and then filled in with the soil of the orchard. The soils best adapted for orchard trees are, first, loams with a subsoil of limestone; second, loams resting on a dry, 
stony subsoil; third, loams rèsting on clay-these should be drained. Light sandy loams, with a subsoil of sand, chalk, and gravel, are not adapted for standard orchard trees, unless the staple of loam is from three to four feet thick.

PROPER DISTANCES FOR PLANTING PYRAMIDAL AND OTHER FRUIT TREES.

Pyramidal pear trees and bushes on quince stocks, to be cultivated as root-pruned trees, for small gardens, four feet apart.

The same, in larger gardens, not root-pruned, six feet apart.

Pyramidal pear trees on the pear stock, root-pruned, six feet apart.

The same, roots not pruned, eight to ten feet-the latter if the soil be very rich.

Horizontal espalier pear trees on the quince stock, for rails or walls, ten feet apart.

Upright espaliers on the quince stock, for rails or walls, four to six feet apart.

Horizontal espaliers on the pear stock, for rails or walls, twenty feet apart.

Pyramidal plum trees, six feet apart.

Espalier plum trees, twenty feet apart.

Pyramidal and bush apple trees on the Paradise stock, root-pruned, for small gardens, three to four feet apart.

The same, roots not pruned, four to six feet apart.

Espalier apple trees on the Paradise stock, fifteen feet apart.

The same on the crab stock, twenty feet apart. 
Peaches and nectarines, for walls, fifteen to twenty feet apart.

Apricots, for walls, twenty feet apart.

Cherries, as bushes and pyramids on the Mahaleb stock, root-pruned, for small gardens, four feet apart.

The same, roots not pruned, six feet apart.

Pyramidal cherries on the common cherrystock, six feet apart.

Espalier cherry trees, for rails or walls, fifteen to twenty feet apart.

Proper distances for trees against dwarf walls, annually or biennially removed (see page 37).

Pears on quince stocks, five feet apart.

Peaches, nectarines, apricots, and plums, five feet apart.

Cherries and apples, five feet apart. 



\section{A P PENDIX.}

THE PEACH TRELLIS OF THOMAS WHTTE, ESQ., MANOR HOUSE, WEATHERSFIELD, ESSEX.

In the autumn of the year 1851, Mr. White, while walking through the grounds here, happened to see my small Ker's trellis with movable lights, and on his return home the idea occurred to him that it might be enlarged, and the principle improved upon, so as to be able to grow fruit enough for a large family. In the autumn of that year, he accordingly built a trellis-house of the following dimensions:-
Length
Width (inside)
Height at back
Height at frent
Rafters (fixed 20 inches apart)
Trellis (15 inches from the glass) .
Sunken path in centre
.80 feet.
.12 feet.
- 8 feet.
.14 inches.
. 14 feet long. 13 feet wide.
- 2 feet deep.

The front and back plates both rest on larch poles about four or five feet apart; a shutter, twelve inches wide, on hinges, forms, with a slip of board, the front wall. The back wall is made with long fagots of brushwood $<$ a double row ; the ends are boarded up, and a door is at each end. Perhaps no gardening structure was ever built so cheaply, and none ever pro- 
duced such marvellous effects. The trees-dwarf and standard trained peaches and nectarines, two or three years trained, twelve of the former and six of the latter-were planted in February, 1852; and in the season of 1854 , only the third year of their growth, they bore 5,000 peaches and nectarines. On one tree of the Noblesse Peach there were 500 peaches, and the same number or more on a tree of the Elruge Nectarine. This seemed enough to ruin the health of the trees, and so-I thought when I heard of it; but when I saw the excessive vigor of the trees, I thought Mr. White and his gardener not so far wrong in allowing them to bear such an enormous crop. The dwarf trees have reached to the top of the trellis and covered it completely.

Mr. White was, I believe, offered the sum that the house cost him-somewhere about $£ 40$ - for his crop of peaches and nectarines in 1854. The vigor of the trees is quite astonishing; the stems of some of them are twelve or more inches in circumference; they are planted inside the front shutter, and laid directly on the trellis. The remarkable success of this simple structure seems owing entirely to the perfection of its ventilation; the front shutter has been open night and day in warm weather, and the air passes gently and constantly through its brushwood back wall, so as entirely to prevent stagnation. The trees have been syringed regularly night and morning, and are in the finest possible health.

As the brushwood wall is unsightly and dangerous in some situations, owing to its capability of harboring rats and mice, we must now see what can be substi- 
tuted for its perfect ventilating property. Hedges to lean-to houses, as I know from experience, are too cold to ripen peaches and nectarines, although highly favorable to the growth of the trees; it therefore appears to me that the perforated bricks, now largely manufactured, could be used with advantage in this way. The wall, eight feet in height, should be built five feet from the ground with common bricks; and then, three feet up to the top for the plate to rest on, with perforated bricks, placed edgewise. In very cold weather in March, when the trees are in blossom, a curtain of calico, or any other convenient material, might be arranged so as to cover this space of the perforated wall at night, and in May it may be removed. for the summer. This perforated space, with the front shutter constantly open, will, in my opinion, be perfect for a peach trellis, and not unsightly.

It will be seen, from what I have said that Mr. White's trellis differs from Mr. Ker's in this way-the roof is fixed, and not of removable lights; the trees are pruned and the fruit is gathered from underneath, so that all the operations of culture are performed under shelter, and in a climate at all times favorable.

Since the above was written, Mr. White has had his fagot-wall removed, and glass placed at the back, at a sharp angle of 30 degrees. Under this are trained peaches and nectarines, which succeed those under the -front glass. The effect is excellent; and the trees, the late warm summer (1858), ripened their fruit well, al though the slope is to the northeast. In cool seasons, it is to be feared, the flavor of the fruit will suffer.

The following letter, from a very clever amateur 
fruit cultivator, will, I think, be found interesting to those who wish to make the most of a small garden:-

\section{"To Mr. Rivers.}

"Dear SrR,-I have derived much pleasure from the cultivation of fruit trees in the different modes introduced by you-as pyramids, bushes, and in pots, under glass; and you will be glad to hear, as I am to tell you, that the pleasure has been greatly enhanced by success. Wishing to have a good many fruit trees, and my garden being a small one, I have resorted to many contrivances to make the most of my space; and knowing that the subject is one interesting to you, I venture to give you an account of some of them.

"About seven years ago, I put down on the east and west borders of one of my squares a row of stout and straight larch poles, eighteen inches in the ground, four feet above it, and three feet apart. These were sheeted, on the side next the walk, with half-inch boards, on the top of which was placed a rail two inches wide; stays were fixed against each end and against the centre, to prevent shaking by the wind; and all got two coats of paint. The entire cost of the structure, exclusive of the poles, which I happened previously to have, was sixpence for each running foot. Against these walls I planted, on the side next the walk, dwarf-trained pear trees on quince stocks, and some plum trees. I then went to the other side of my wall, and planted there as many more trees-placing them intermediately between those at the opposite side, so that the roots of one should not interfere with those of another. I had thus, on the space usually occupied 
by a single line of open espaliers, a double number of fruit trees, one half of them having an eastern and the other a western wall. The second year from planting I was rewarded by a nice crop: and although the trees were then young, the fruit, had I been disposed to sell it, would have realized more than the original cost of the walls : and this last year I have had against them as fine crops of Beurré d'Amanlis, Thompson's, Gansel's Bergamot (double grafted on the quince), Williams's Bon Chrétien, Chaumontel, and other pears, as need be desired, and also fair crops of greengage, purple gage, and Kirke's plums.

"I have not adopted wooden walls along my north or south borders, because one side would be useless; but instead of them I nailed cheap calico at the north side of some of my espalier rails which run east and west, thus giving to the trees next the walk a southern aspect. The calico is secured to the posts and to the rail at top by tape, in which numerous tacks are driven. When first put up, it got a good coat of oil and black paint, and, with the exception of a few small holes made by accident, and which can easily be repaired, it is now, in its third year, strong as ever, tight as a drum, and having the appearance and something of the sound of sheet-iron. I grew against those cotton walls this past year as fine crops of Joséphine de

- Malines, Maréchal de la Cour, Beurré d'Aremberg, and Marie Louise pears, as the most ardent horticulturist could desire.

"There is another mode in which I have cultivated fruit trees; but it is right to say that the idea, although I had not seen it put into practice elsewhere, was taken 
by me from the 'Orchard and Fruit Garden,' by Mackintosh. I cut back to three or four buds some maiden pear trees grafted on the quince, and when they threw out three shoots I tied them down, so as to give to each a horizontal direction. The following year I placed round them eight stakes, about eighteen inches from the stem, and equidistant from each other, and outside those stakes the branches were trained in a spiral form. I transferred some of those to the borders of the walk leading to my orchard house. The stakes round, which the branches are trained are painted white, and secured in their proper positions by a hoop of round iron fastened inside the top. The trees look well and bear well. A Passe Colmar managed in this way was loaded with fruit last year, and attracted much attention. I consider that this plan possesses many advantages-the trees may be kept near the ground, and thus have more heat; the air circulates freely inside; then the sun shines on every branch during some portion of the day, and the fruit, however large, is not liable to be blown down. The method might be called, not inappropriately, after that ancient and useful instrument the corkscrew; but, if you find the term too homely, let it be en tire-bouchon.

"With best wishes for your long life and health, both for your own sake and for the interests of horticulture, on which you have already conferred so many benefits,

"I remain, dear Sir,

"Yours truly,

"Joseph Meadows." 


\section{TEE GROTSD TLERT.}

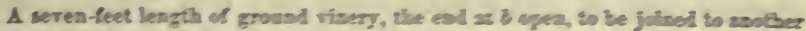
seres-feet leagth with a closed eod, at ciluer ofive

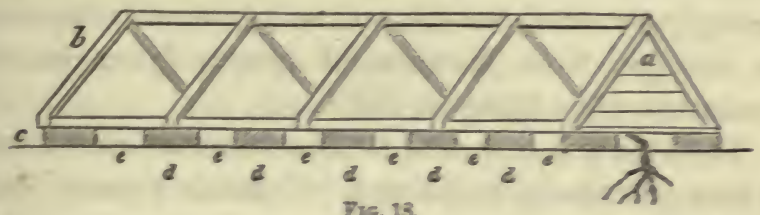

a Aperture 4 leches deeg, ive the ecreas of but ic.

8 The epen ed, to be allod to as plessure.

e Groend level.

¿ Brieks.

- Interstioes between bricks fie tentilative

The "Curate's Vinery," described in the tenth edition, was contrired by Dr. S. Newington, of Ticehurst- "Sigma"-and consisted of a ridge of glass placed over a furrow lined with slates, so that the bunches of grapes were suspended in the furrow, and in warm seasons ripened well. One objection to the furrow was its liability to be filled with water in wet weather, in low situations and heary soils. I therefore sought to remedy this, and one dar, about the end of June, 1860, I found myself looking into my original "Curate's Vinery," and admiring the rines then in blossom, although those within a few yands of it, growing in the open air, were scancely in full leaf. I pictured to myself the bunches of grapes suspended from the rines in the warm, moist atmosphere of the trench lined with slates. My thoughts then reverted to my boyish grape-loring days, when, in an old vineyard planted by my grandfather, I always looked for some ripe grapes about the ead of September; and I vividly remembered that I alrays found the best and 
ripest bunches with the largest berries lying on the ground, and if the season were dry and warm, they were free from dirt, and delicious (I think I always strongly accented the $d e$ ), and so I gradually travelled in thought from bunches of grapes lying on the ground to idem lying on slates.

The idea was new, and I commenced at once to put it into practice by building a "Curate's Vinery" on a new plan.

I therefore placed two rows of bricks endwise (leaving four inches between each brick for ventilation) on a nice level piece of sandy ground, and then paved between them with large slates ("duchesses") placed crosswise. I am, however, inclined to think that tiles may be preferable to slates; absorption of heat is greater and radiation slower. On the bricks I placed two of the ridges of glass, as given in the foregoing figure, each 7 feet long, and thus formed my vinery, 14 feet in length. The vine lies in the centre of the vinery, and is pegged down through the spaces between the slates. One vine will in the course of two years fill a vinery of this length; but, to reap the fruits of my project quickly, I planted two vines, one in the centre, the other at the northeast end; for these structures should stand northeast and southwest. One of these vines, which had been growing in a pot in the open air, was just beginning to show its fruit-buds-it was quite the last of June-its fruit ripened early in October, and were fully colored and good in spite of the cloudy, cold autumn. My black Hamburgh grapes in my ground vineries were fully ripe in 1862 by the 
first week in October. I therefore feel well assured that grapes lying on a floor of slates, such as I have described, will ripen from two to three weeks earlier than in vineries of this description with a furrow, and as early as grapes in a common cold vinery. Black Hamburghs and other kinds of grapes not requiring fire heat may thus be grown in any small garden at a trifling expense. I am, indeed, disposed to hope that the Frontignans, and nearly all but the Muscats, may be ripened by this method, so intense is the heat of the slated floor on a sunny day in July.

Some persons may think that the heat would be scorching, and that the leaves and grapes would alike become frizzled; but few gardeners know the extreme heat a bunch of grapes can bear. I remember a lady friend, who had resided some time at Smyrna, telling me that one afternoon at the end of summer, when the grapes were ripening, she was sitting in her drawing-room and adniring some large bunches of grapes hanging on a vine which was growing against a wall in the full sunshine. Knọwing the danger of going into the open air without a parasol, she rushed out, cut a bunch of grapes, and returned to her seat in the shady room. The bunch of grapes was so hot that she was obliged to shift it from hand to hand. I observed in the hot weather we had in July, 1859, one or two branches of Muscat grapes, nearly touching the chimney of the stove in which a fire was ke'pt up every morning, gradually turning into raisins. I felt some of them when the sun was shining on them; they were not burning hot, but next to it.

1 allowed them to dry into raisins, and very fine 
they were, but not better than the finest imported from Spain.

With respect to the superior ripening power of slates or tiles placed on the surface of the earth, I was much interested in once hearing a travelled friend say that, when he was at Paros, he observed many vines trained up the marble rocks peculiar to the island; and in all cases the grapes lying on the surface, which was almost a continuous mass of rock, were ripe, while those a few feet from it, on the same vine, some of the branches of which were trained up the wall-like rocks, were quite green. In telling me this, he said he was never more impressed with the ripening power of the earth's surface.

I have, in giving the figure and description of the ground vinery, made it adapted for one vine, the width of it being 2 feet 6 inches only. If this width be increased to 3 feet 6 inches, two vines can be trained under the same roof 14 inches apart, and thus at a trifling additional cost double produce can be obtained. I have very recently planted some peach trees in one of these slate-paved vineries, and feel assured that very early and very fine peaches can be grown in such places. I have managed my trees in this way-I took two pyramids full of blossom-buds, cut off the shoots on one side so that the stem would lie flat, and I then pegged it down with hooks made of stout iron wire, thrusting them into the soil between the interstices of the slates.

Cultivators will think of red_spider making his home in such (fur him) a happy, hot place; but he may be made so uncomfortable by keeping flowers of 
sulphur strewed over the slates till near the ripening season, that no inconvenience need be apprehended. It will be perceived that the ventilation is all lateral, and, on the same principle as that of my orchardhouses, nothing can be more perfect. In the figure it will be seen I have left a small aperture under the apex of the roof for the escape of rarefied air. In very hot weather this may be useful, but in my slatefloored ground vineries I have not done this, and yet the ventilation is perfect. I have not yet ascertained in what manner the heated air escapes. The ventilating apertures are all on the surface of the soil, and at the same level; but I suppose it stoops to get out, having no other mode of egress.

\section{DIMENSIONS OF GROUND VINERIES.}

\section{No. 1, for a single vine in centre.}

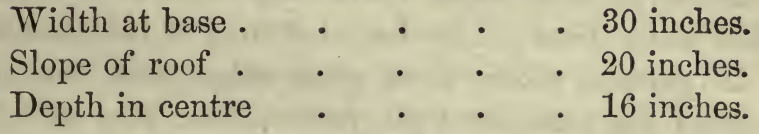

No. 2, for twoo vines 14 inches apart.

Width at base . Slope of roof . Depth in centre
- 42 inches.

- 28 inches.

- 20 inches.

These dimensions need not be arbitrary, for ground vineries of larger dimensions may be made with every chance of success, and Hamburgh grapes grown in Bedfordshire instead of cucumbers; for no part of England can be more favorable to grape culture than the fertile, sandy districts of a portion of that county. We have heard of forty acres of cucumbers being grown for pickling, and one day we may hear of forty 
acres of grapes in ground vineries in some favorable locality. To form the vinery No. 1, p. 125, two sevenfeet lengths are required; these I find from experience are better made of wood than iron, which is heavy and expensive; they are now made three feet wide at base, and sold by Mr. J. Rivett, Stratford, Essex, at from 65s. to $70 s$. per dozen, unglazed and unpainted. Their size may also be increased to 3 feet 6 inches, as in No. 2, but they must then be placed on a wall two bricks in height, leaving apertures, four or five inches wide and six inches deep, for ventilation; this increase of ventilation is absolutely necessary with No. 2. The glass used should be $21 \mathrm{oz}$., as $16 \mathrm{oz}$. is too slight. As the vines in ground vineries often put forth their young shoots early in May, and are apt to be injured by a severe May frost, it is good practice to keep some refuse hay strewed over the glass when there is any chance of frost in that month.

In gardens where these glass ridge roofs are not wanted for vines or fruit tree culture, they will be found most useful. They may be placed on any warm border on bricks; and early peas, French beans, and many other early vegetables, requiring protection from spring frosts, be grown under them with advantage. For the cultivation of early strawberries they are invaluable, as they not only hasten the ripening period, but protect the fruit from heavy summer showers, often so injurious to the crop, and also from birds. Strawberry plants, to be cultivated in ground vineries, s'ıould be planted early in autumn, in narrow beds of two or three rows, the plants close together in the rows, so as to take full advantage of the glass-covere 1 
space. The rows should be 9 inches apart; the beds should be made every season on a fresh piece of rich soil; and as much fruit as can possibly be grown in such a limited space must be the aim of the cultivator. In all cases the ridges should be placed on bricks, with spaces between them. Ventilation is then secured; and even cauliflower plants in winter will do well without the constant attention to "giving air," so necessary in the old garden frame culture. Lettuces, for early salads, succeed admirably in these structures; they should be planted in October. In gardens that are confined and very warm, I repeat, it may be necessary to have a small opening left at the top, at $a$, in the figure, just under the ridge, to let out the heated air, and two rows of bricks instead of one; but my vineries stand in a very exposed place, and do not require it. I feel that I ought to tell my readers the perfect success of my ground vineries this season (1864). In four of them are growing four varieties, one in each vinery, viz., Trentham Black, Black Hamburgh, Buckland Sweetwater, and La Bruxelloise. On these four vines are 100 bunches; their berries now (August 10) swelling rapidly. The only culture they have had has been taking off about half the number of bunches they produced, thinning the berries and stopping the shoots. No syringing, no watering has been required, and not a red spider or any other blight is to be seen.

Any suburban garden 10 yards square, if in a sunny situation, may have one or two of these vineries; the occupier may grow his own black Hamburgh grapes known by most Londoners as "Hothouse grapes." 


\section{POSTSCRIPT.}

September 8, 1865.

Such a season as the present has never been experienced since the invention of ground vineries. A fine vine here of the Trentham Black grape occupies five seven-feet lengths, and is, of course, thirty-five feet long; this is bearing fifty nice sized bunches of grapes, now fully ripe. Another vine, the Black Hamburgh, is also bearing a fine crop of sixty-three medium-sized bunches, the grapes full-sized, finely colored, and fast approaching to ripeness. There seems to be a most agreeable and animating prospect of these neat-looking and most useful structures occupying thousands of small gardens, and giving the luxury of fine ripe grapes to many who are capable of appreciating and enjoying them.

The first idea of one vine only occupying two seven-feet lengths is put to rest, for in a good soil the vines are so vigorous that, although they may be shortened so as to be confined to fourteen feet, there is no reason why one vine should not extend to one hundred feet, adding annually one or two lengths as required. I am inclined to hope that I shall live to see my favorite Trentham Black reach that length.

September 21, 1865.

I find to-day that the grapes on bunches hanging from the upright spurs of my Black Hamburgh vine, just under the apex of the roof of one of my ground vineries, and a trifle over one foot from the ground- 
in short, just where they would hang if suspended from a wire in the centre-are nearly or quite ripe; the bunches on the slates are not quite in so forward a state of ripeness, but the ripest of all are the bunches hanging so that their tips touch the slates. This, I hope, has settled the question, so that we may now have our vines trained to wires in ground vineries, and calculate that, if the bunches are suspended so as to touch or partially lie on the slates, thus benetiting by their radiation of heat, grapes will ripen well. 
n.

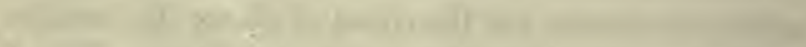

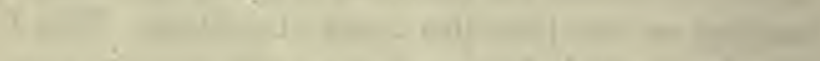

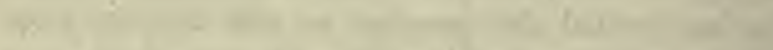

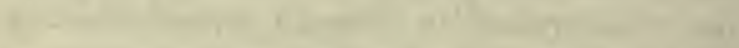

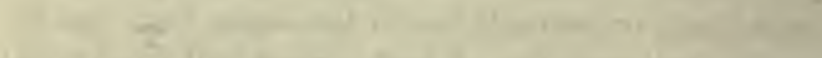

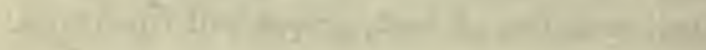
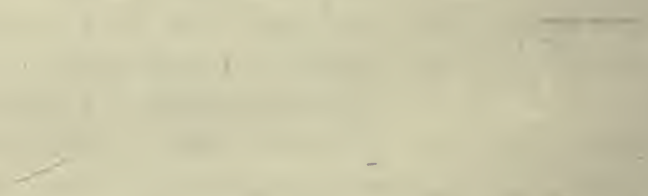

.

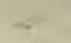




\section{INDEX.}

65

Burr kuot stock . . . . . . . . 61

Bushes on Paradise stock . . . . . . 67

Bushes for a market garden . $\quad$ • $\quad$. $\quad$. 69

Dormant buds, to notch . $\quad$. $\quad$. . . 64

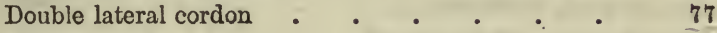

Doucin stock . . . . . . . . 60

In pots $\quad . \quad . \quad . \quad . \quad . \quad . \quad .62 .66$

Pomme de Paradis . . . . . . . 62

Pyramid, summer pinching of . . . . . 66

Pyramidal, on crab $\quad . \quad+\quad . \quad . \quad . \quad . \quad$. 80

Root-pruning of . . . . . . . 63

Selection of sorts $\quad . \quad . \quad \cdot \quad . \quad . \quad . \quad .67 .68$

Summer pinching of bushes . . . . . 68

Single lateral cordon . $\quad . \quad$. . . . 75

To keep hares from . . . . (note) 69

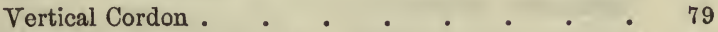

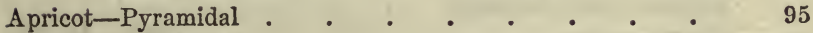

Cherry-As bushes . . . . . . . . 85

Biennial removal of . $\quad . \quad$. . . 92

$\begin{array}{llllll}\text { Cure for Aphis . } & \text {. } & \text {. } & \text { (note) } & 89\end{array}$

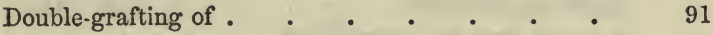

On the common stock $\quad$. $\quad . \quad$. $\quad$. $\quad$. 91

On the Mahaleb stock . $\quad . \quad . \quad . \quad . \quad . \quad 85$

Pruning of $\quad . \quad+\quad . \quad . \quad . \quad . \quad . \quad 85$

Pyramidal . . . . . . . . 87

Selection of sorts $\quad . \quad . \quad . \quad . \quad . \quad . \quad .89 .94$

Summer pinching of $. \quad . \quad . \quad . \quad . \quad . \quad 87$

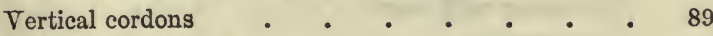

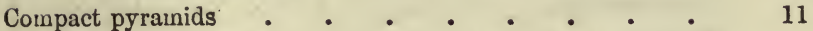


Currant-Pyramidal

Double-grafting of fruit trees . . . . . . 102

Dwarf walls, proper distance for trees . . . . . 37

Fig, as half-standards and bushes . . . . . 97

Filbert, as standards . $\quad . \quad$. $\quad . \quad$. $\quad . \quad$. 96

Fruit trees-Advantages of root-pruning of . . $\quad \cdot 48$

Biennial removal of . . . . . . 98

Distances to plant . . . . . . 112

Glass fruit ridge . . . . . . . . 78

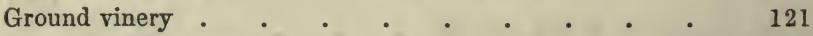

Labels for fruit trees . . . . . . (note) 15

Market garden bush pear trees . $\quad . \quad$. . . 54

Medlar-Pyramidal

Moss on trees, to destroy . . . . . (note) 101

Old fruit trees, root-pruning of . . . . . . 47

Peach border, how to prepare . . . . . . 106

compost for . . . . . . . . . $\quad$. 99

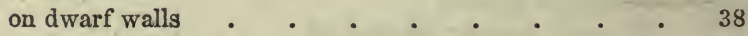

trellis . . . . . . . . . 115

Pear-As a hedge . . . . . . . 43

As bushes on the quince stock $\quad$. . . . 17

Biennial root-pruning of wall trees . . . . 40

$\begin{array}{lllllll}\text { Budding with fruit buds } & \text {. } & \text { (note) } 6\end{array}$

Bushes for a market garden . . . . . 54

Corkscrew, training of . . . . . . 120

Dormant buds, to notch . . . . . . 6

Double-grafted . . . . . (note) 15. 103

Espaliers on quince stocks . . . . . . 40

For dwarf walls $\quad$. $\quad . \quad$. $\quad . \quad$. 35

Gathering the fruit . . . . . . 56

Keeping fruit in a greenhouse. $\quad . \quad$. $\quad . \quad . \quad 59$

Mature pyramid . . . . . . . . 7

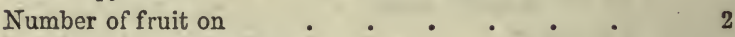

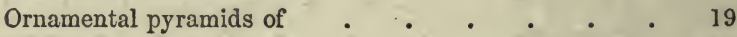

Planting . . . . . . . . 50

Proper time to plant . . . . . . . 2

Protecting wall trees . . . . . . 108

Protectors for . . . . . . . 20

Pruning . . . . . . . . . 10 
Pear-Pyramid on the pear stock

PAGE

Quenouille

R(ıt-pruning of, on the pear stock . . . . 44

Root-pruning on quince . . . . . . 12

Semi-pyramids for walls . . . . . 28

Shortening leading shoots . . . . 4 4.6.9

Sorts for bushes . . . . . . . 20

pyramids . . . . . . . 15

upright cordons $\quad . \quad$. $\quad . \quad$ - 29

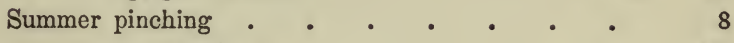

top-dressing . . . . . . . 53

Thinning blossom buds . $\quad . \quad$. $\quad . \quad$. 2

To store for winter $\quad$. $\quad$. $\quad$ • . 58

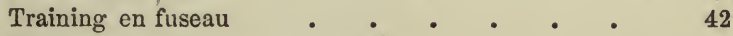

Under glass $\quad . \quad$. $\quad . \quad$. . . 32

Upright cordon training . . . . . . 23

Upright cordons for trellises . . . . . 31

walls.$\quad \cdot \quad \cdot \quad \cdot \quad \cdot \quad 24$

Wooden walls for $\quad$. $\quad$. $\quad$. 118

Young pyramid . . . . . . . . 4

Plum-As bushes $. \quad . \quad . \quad . \quad . \quad$. 84

On sloe . . . . . . . . . . 82

Pyramidal . . . . . . . . 81

Selection of sorts . $\quad . \quad+\quad . \quad$. $\quad . \quad 48$

Pyramidal fruit trees, summer pinching of . . . . 11

alternate root-pruning of . . (note) 12

labels for . . . . (note) 15

planting . . . . . (note) -50

Standard orchard trees . . . . . . . . 109

Strawberries in ground vinery . . . . . . 126 


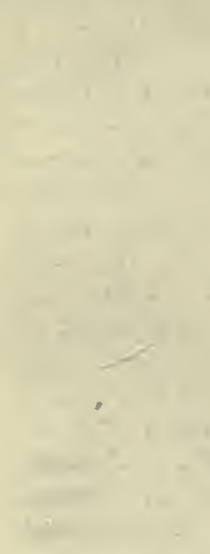

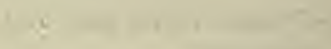

an

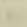

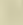

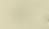

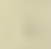

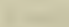

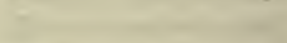

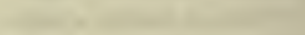

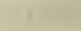

(n)
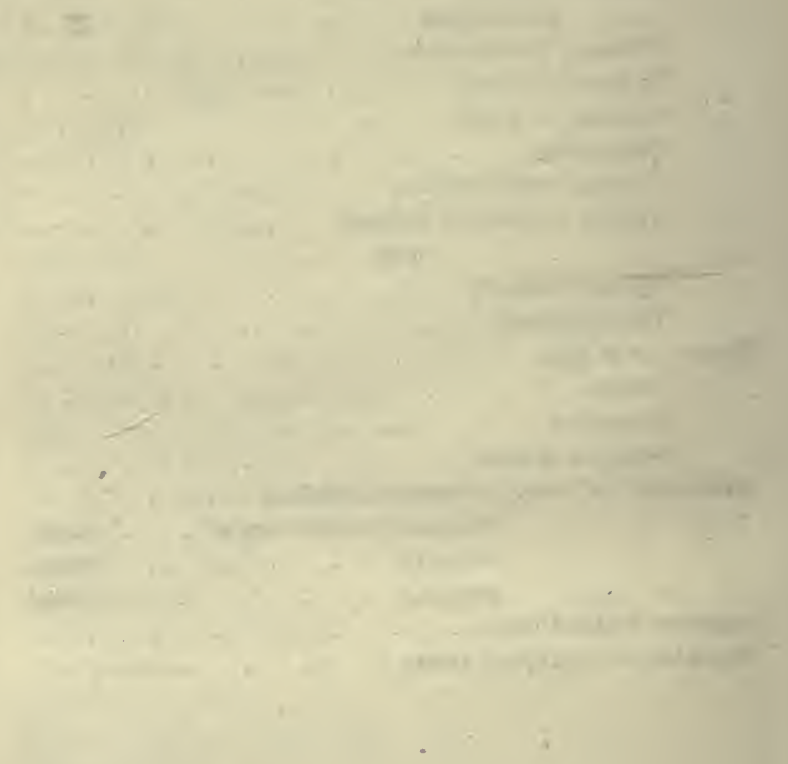

$1=$
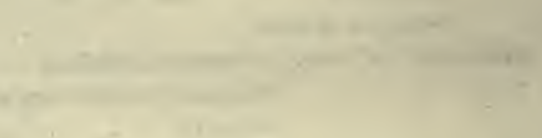

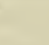

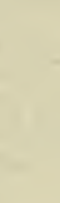$$
x^{2}
$$ 


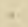

$-$ 
UNIVERSITY OF CALIFORNIA

BRANCH OF THE COLLEGE OF AGRICULTURE

THIS BOOK IS DUE ON THE LAST DATE STAMPED BELOW

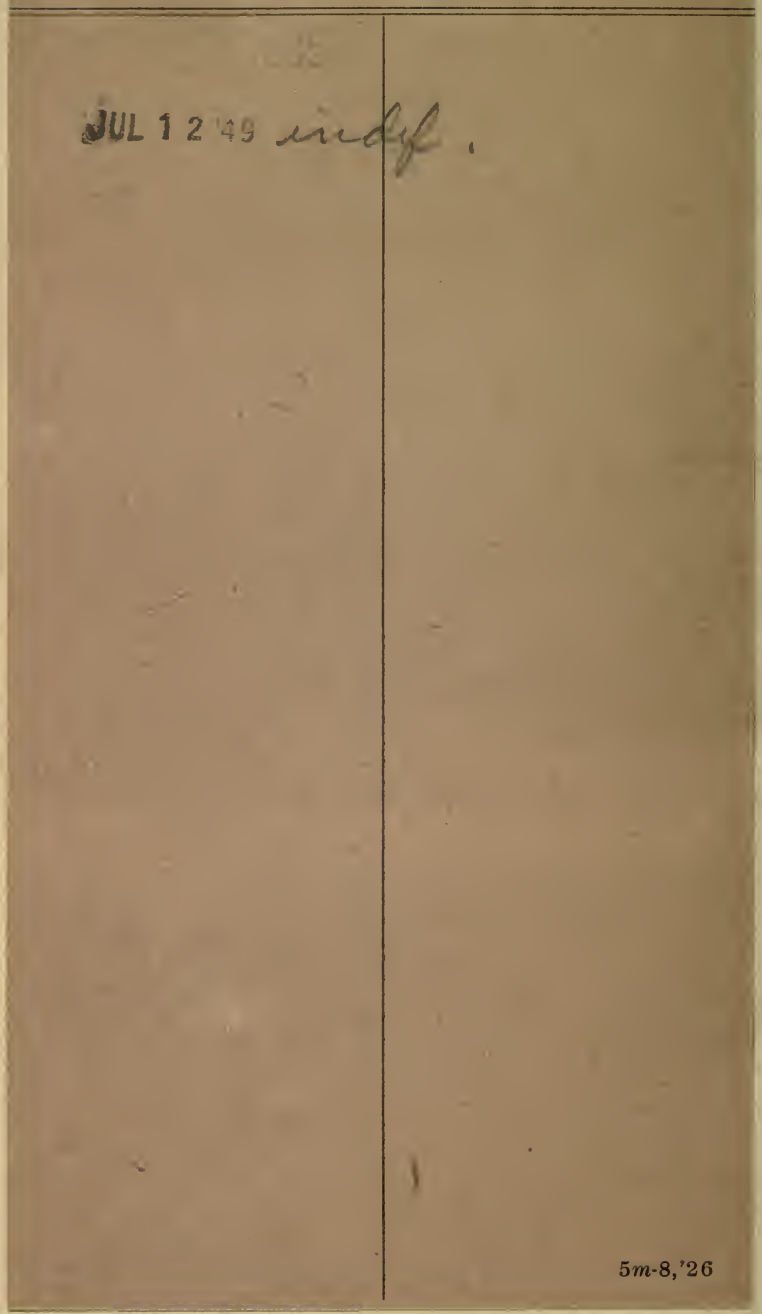




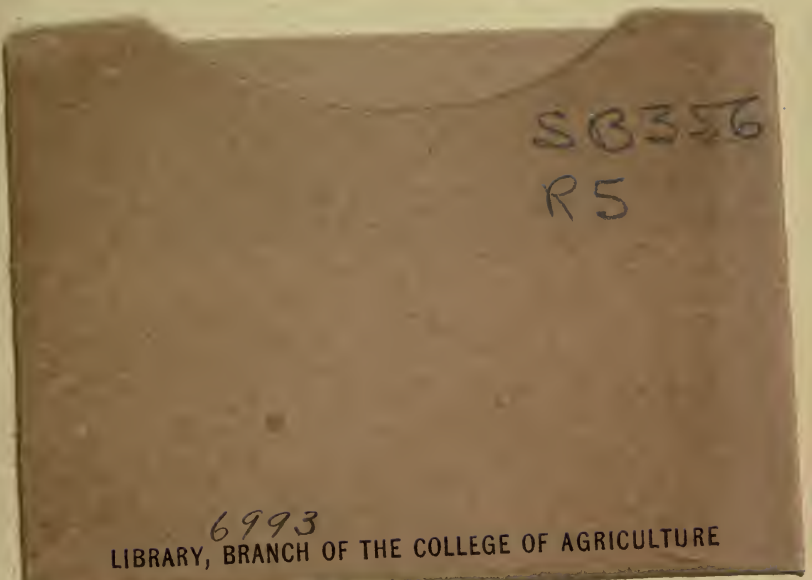


